\title{
LA PRESENCIA DE VALENCIANOS Y ARAGONESES EN LA DOCUMENTACIÓN NOTARIAL CAGLIARITANA DEL SIGLO XV
}

\author{
THE PRESENCE OF VALENCIAN AND ARAGONESE \\ IN THE NOTARIAL DOCUMENTATION FROM CAGLIARI \\ OF THE 15th CENTURY ${ }^{1}$
}

\section{CONCEPCIÓN VILLANUEVA MORTE ${ }^{2}$ Universidad de Zaragoza}

\begin{abstract}
Resumen: El objeto de este artículo es estudiar las relaciones comerciales entre la Corona de Aragón y Cerdeña (Cagliari), y la movilidad geográfica en la transición de la Edad Media a la Moderna, para valorar las corrientes de tráfico y el balance de vínculos trazados entre ambos territorios. Para ello presentamos los primeros resultados sugestivos de una cata realizada sobre la documentación notarial cagliaritana del siglo XV en relación a la presencia de valencianos y aragoneses allí asentados, en aras de comprender la diferencia comparativa de enfoque con respecto al análisis derivado de estas fuentes históricas sardas y aquellas otras ibéricas, que ya han sido exploradas en investigaciones anteriores.
\end{abstract}

Palabras clave: Comercio; Movilidad geográfica; Documentación notarial cagliaritana, S.XV; Valencianos y aragoneses.

\begin{abstract}
The aim of this article is to study the commercial activity between the Crown of Aragon and Sardinia (Cagliari), and the geographical mobility that it was generated in the transition from Medieval to Modern Age, that serves to value the traffic currents and the balance of traced bonds. For it we present the first suggestive results of one taste which it has been carried about notary documentation of Cagliary in the 15th century in relation to the presence of Valencian and Aragonese there seated, for the sake of understanding the comparative difference of focus with regard to the derivative analysis of these historical sources of Sardinia and those other ones Iberian, that have already been explored in previous investigations.
\end{abstract}

Keywords: Commerce; Geographical mobility; Notary documentation from Cagliari; 15th c., Valencian,Aragonese.

\footnotetext{
${ }^{1}$ El presente estudio se integra en el marco de un proyecto de investigación "Documentación medieval sobre los reinos de Aragón y Valencia en los Archivos Históricos de Cerdeña", que fue financiado por el Programa Europa XXI de Estancias de Investigación de la Caja de Ahorros de la Inmaculada en colaboración con la Dirección General de Aragon (CONSI+D), con referencia $\mathrm{CH}$ 18/04, fruto de una estancia trimestral que realicé durante los meses de junio a septiembre de 2004 en el Istituto di Storia dell'Europa mediterranea de Cagliari (CNRS Ittalia), bajo la supervisión de la investigadora Maria Eugenia Cadeddu, a quien agradezco su orientación tanto en la búsqueda de material documental como en la recopilación bibliográfica mediante el sondeo de las principales bibliotecas que gestionaba el antiguo Istituto di Rapporti Italo-Iberici.

${ }^{2}$ Becaria de Investigación Postdoctoral del Ministerio de Educación y Ciencia con el proyecto de referencia ref. EX-2006-0832 titulado: "Relaciones comerciales y diplomáticas entre el estado de Milán y la Corona de Aragón en la Baja Edad Media" desarrollado en el Dipartimento di Scienze della Storia e della Documentazione Storica de la Università degli Studi di Milano (Italia), bajo la dirección de la profesora Patrizia Mạinoni. Este trabajo se adscribe a su vez en el proyecto de investigación interuniversitario: Migraciones, élites económicas e identidades culturales en la Corona de Aragón (1350-1500), propuesto por Paulino Iradiel Murugarren, catedrático del Departamento de Historia Mediẹval de la Universidad de Valencia, y subvencionado por el Ministerio de Educación y Ciencia durante 2006-2008 (ref. HUM2005-04804/HIST).
} 


\begin{abstract}
SUMARIO
1. Estado de la cuestión y bases bibliográficas.- 2. Fuentes documentales empleadas: los notarios cagliaritanos y sus protocolos.- 3 . Las relaciones comerciales entre Valencia y Cerdeña en el siglo XV.- 4. El reflejo de las relaciones entre Cagliari, Valencia y Aragón en la vida cotidiana.- 5. Otros modelos de investigación desarrollados en las islas del Mediterráneo.- 6. Conclusión.- 7. Apéndice documental.
\end{abstract}

\title{
1. ESTADO DE LA CUESTIÓN Y BASES BIBLIOGRÁFICAS
}

Para aproximarnos mínimamente a la importancia que ha tenido la tradición historiográfica en el terreno de la historia bajomedieval de Cerdeña debemos saber que la producción de escritos de interés artístico-cultural alcanzó el mayor número de estudios e investigaciones durante el pasado siglo XX e inicios del XXI, seguido de cerca por aquellos de fondo económicosocial y, posteriormente, por los de implicación jurídico-institucional y por los de ediciones de documentos, estos últimos no siempre precedidos de estudios críticos.

El número de trabajos dedicados al estudio de la economía y de la sociedad testimonian un interés más evidente por la situación económica que por el aspecto social. De modo particular, hay frecuentes referencias a la actividad comercial y a las rutas mediterráneas, pero también comparecen un discreto número de escritos sobre las cecas y la monetización, sobre la pesca del coral y sobre el fenómeno de la piratería. Por cuanto concierne a las implicaciones sociales, han sido afrontados sobre todo los procesos de infeudación y los fenómenos de población y despoblamiento, mientras que una pequeña contribución es destinada a la profundización de las problemáticas ligadas a la presencia hebrea en la isla. No faltando tampoco algunas obras relativas a la alimentación y a la vida cotidiana ${ }^{3}$.

Descendiendo a un nivel particular de autores, y en relación a nuestro proyecto de investigación, nos interesa fundamentalmente la consulta de obras maestras sobre la línea política y económica, y sobre consiguientes miras aragonesas vueltas a Cerdeña. Existen los trabajos de Marco Tangheroni, en los que se pone de manifiesto la relevancia de la componente económica en la elección catalano-aragonesa de ocupar la isla ${ }^{4}$; Alberto Boscolo, que nos ofrece un cuadro de la visión del período ofrecido por Jerónimo Zurita y un somero análisis de la documentación sobre economía y sociedad en época de

\footnotetext{
${ }^{3}$ Valentina NONNOI, Il Regno di Sardegna in epoca aragonese. Un secolo di studi e ricerche (1900-1999), Pisa, Ets, 2001, p. 54.

${ }^{4}$ Marco TANGHERONI, Alcuni aspetti della politica mediterranea di Giacomo II d'Aragona alla fine del suo regno "Annali della Facoltà dì Lettere e Filosofia dell'Università di Cagliari", XXXII (1969), pp. $103-167$.
} 
Alfonso el Benigno ${ }^{5}$; Francesco Giunta ${ }^{6}$ y Francesco Cesare Casula ${ }^{7}$. Por cuanto concierne a la economía, hay que citar la exploración archivística realizada por Francesco Loddo $\mathrm{Canepa}^{8}$; algunos estudios particulares como los de Ciro Manca ${ }^{9}$ y Giuseppe Meloni dirigidos principalmente al estudio de las rutas comerciales y, en este sentido, a los motivos económicos que han contribuido al surgir de las ambiciones aragonesas respecto a Cerdeña ${ }^{10}$. También de la vertiente económica se han ocupado Bruno Anatra ${ }^{11}$, Marco Tangheroni $^{12}$ y aún Pinuccia Simbula ${ }^{13}$.

Frente a estos clásicos ensayos, en los últimos decenios, la atención de los estudiosos por la historia sarda cuatrocentista en general, y por la economía en particular, ha crecido de modo considerable. Entre ellos destacan las investigaciones llevadas a cabo por Gabriella Olla ${ }^{14}$ y su equipo, que

${ }^{5}$ Alberto Boscolo, Geronimo Zurita ed i problemi mediterranei della Corona d'Aragona en "Actas del VII Congreso de Historia de la Corona de Aragón", Barcelona, 1962, pp. 187-228; y Documenti sull'economia e sulla società in Sardegna all epoca di Alfonso il Benigno, Padova, CEDAM, 1973.

${ }^{6}$ "Francesco GIUNTA, La Sardegna e la nuova politica mediterranea di Giacomo II d'Aragona en "VI Convegno Internazionale di Studi Sardi", Cagliari, 1962.

${ }^{7}$ Francesco Cesare CASULA, Il 'Regnum Sardiniae et Corsicae' nell'espansione mediterranea della Corona d'Aragona. Aspetti politici en "Actas del XIV Congreso de la Corona de Aragón", Sassari, I, 1993, pp. 39-48.

${ }^{8}$ Francesco LODDO CANEPA, Nuovi documenti sardi dell'Archivio della Corona d'Aragona in Barcellona rintracciati durante l'esplorazione compiuta nell'agosto 1954 en "Annali della Facoltà di Lettere, Filosofia e Magistero dell'Università di Cagliari", XXII (1954), pp. 633-675; y del mismo Stato economico e demografico di Cagliari allo spirare del dominio aragonese in rapporto all'attività commerciale mediterrạnea, "Studi Sardi", XIV-XV (1955-57) [1958], parte II, pp. 162-179, donde ya se permitió evidenciar la importancia del estudio de la fuente notarial para un mejor conocimiento de la vida económica de Cagliari.

${ }^{9}$ Ciro MANCA, Fonti e orientamenti per la storia economica della Sardegna aragonese, Padova, CEDAM, 1967; Il Libro dei Conti di Miquel Ça-Rovira, Padova, CEDAM, 1969 y Colonie iberiche in Italia nei secoli XIV e XV, "Anuario de Estudios Medievales", 10 (1980), pp. 505-538.

${ }^{10}$ Giuseppe MELONI, Contributo allo studio delle rotte e dei commerci mediterranei nel Basso Medioevo, "Medioevo. Saggi e Rassegne", 3 (1977), pp. 117-130; y Note sull'economia della Sardegna basso medioevale en La Sardegna nel mondo mediterraneo "Atti I Convegno Internazionale di Studi storico-geografici" a cura di M. Brigaglia, Sassari, 1981, pp. 315-323.

${ }^{11}$ Bruno ANATRA, Economia sarda e commercio mediterraneo nel basso medioevo e nell'età moderna en B. Anatra; A. Mattone; R. Turtas, L'età moderna dagli aragonesi alla fine del dominio spagnolo, a cura di M. Giudetti, vol. III' della Storia dei Sardi e della Sardegna, Milán, Jaka book, 1989, pp. 109-216.

${ }^{12} \mathrm{M}$. TANGHERONI, Commercio e navigazione nel Mediterraneo medioevale Roma, 1978 y Aspetti del commercio dei cereali nei paesi della Corona d'Aragona. La Sardegna, Cagliari, CNR, 1981; y Il 'Regnum Sardiniae et Corsicae' nell'espansione mediterranea della Corona d'Aragona. Aspetti economici en La Corona de Aragón en Italia (secc. XIII-XVIII) "Actas del XIV Congreso de la Corona de Aragón”, Sassari, I, 1993, pp. 49-88.

${ }^{13}$ Pinuccia Franca SIMBula, Corsari e pirati nei mari di Sardegna, Cagliari, CNR, 1993 y Navigare nel Medioevo en "VI Settimana della Cultura Scientifica" (Sassari, 1996), Sassari, Ministero per i Beni Ambientali e Culturali, 1997, pp. 71-74.

${ }^{14}$ Gabriella Olla REPETTO, La società Cagliaritana nel '400 en Cultura Quattro-Cinquecentesca in Sardegna. Retabli, restauri e documenti (Catalogo della Mostra), Cagliari, 1985, pp. 1924: La donna ebrea a Cagliari nel "400, "Anuario de Estudios Medievales", 18 (1988), pp. 551562 ; en colaboración con Carla FERRANTE, L'alimentazione a Cagliari nél "400, "Medioevo. Saggi e Rassegne", 14 (1989), pp. 9-77; La donna cagliaritana tra "400 e '600', "Medioevo. Saggi e Rassegne"' 11 (1986), pp. 171-207; La presenza ebraica in Sardegna nei secoli XIV e $X V$, "L'Algher", 23 (1992), pp. 9-16 y editado también en "Bollettino Bibliografico e Rassegna Archivistica e di Studi Storici della Sardegna”, 16 (1992), pp. 25-36; y L'organizzazione del lavoro a Cagliari tra '400 e '500: La confraternita dei falegnami en Sardegna, Mediterraneo e Atlantico tra Medioevo ed Età moderna. Studi storici in memoria di Alberto Boscolo, a cargo de 
hablan de una clara recuperación económica insulana en el transcurso del siglo $\mathrm{XV}$, desembocando en otros evidentemente conocidos de Mario del Treppo ${ }^{15}$, hasta los más recientes de Corrado Zedda ${ }^{16}$ y Sergio Tognetti ${ }^{17}$.

En definitiva, no existe una investigación profunda y específica relativa al complejo mundo de las relaciones económicas y sociales entre el triángulo formado por Aragón-Valencia-Cerdeña. La razón probablemente se deba a que la documentación catalana custodiada en el Archivo de la Corona de Aragón se descubrió bastante tardíamente (a partir de los años 50 del Novecientos). Lo que sí hay son ciertos trabajos acerca de las mercancías y objetos comercializados entre Cerdeña y Valencia, y sobre algunos mercaderes y artesanos que participaron en la campaña de conquista de la isla. Sin embargo, el tema de la movilidad poblacional es más difícil de aprehender porque se trata de un aspecto muy complejo y de reciente actualidad.

La propuesta del estudio aquí planteado se basa en abordar un sondeo heurístico razonado de la documentación medieval que conservan los diferentes archivos históricos de la isla de Cerdeña sobre los antiguos reinos de Aragón y Valencia, así como la consulta de sus agregados bibliográficos ya realizados sobre esta amplia temática objeto de atención. Con todo, su originalidad no radica en proponer una novedosa perspectiva de investigación, sino en aportar una notable contribución documental, ofreciendo, tras el cotejo con lo publicado al respecto por otros autores, un enfoque complementario y comparativo a la hora de ahondar en los resultados expuestos y volcados ya en otros ensayos que nos han precedido.

\section{FUENTES DOCUMENTALES EMPLEADAS: LOS NOTARIOS CAGLIARITANOS Y SUS PROTOCOLOS}

El Archivio di Stato di Cagliari conserva la documentación, muy lagunosa, discontinua y fragmentaria, de ocho notarios del Cuatrocientos, que desarrollaron su actividad en la capital del reino sardo en la segunda mitad del siglo, escriturando en el período temporal comprendido desde 1430 hasta 1511. Se trata de los notarios Pietro Baster, cuya documentación comprende los años 1430-1433, Giovanni Garau (1441-1460), Pietro Steve (1456-1465), Stefano Daranda (1448-1458), Pietro Durante (1459-1463), Andrea Barbens

L. D’Arienzo, Roma, 1993, pp. 429-449, entre otros.

${ }^{15}$ Mario DEL TREPPO, Politica e commercio dei grani nei paesi della Corona d'Aragona nel secolo XV en "Atti dell'Accademia Nazionale di Scienze Morali e Politiche di Napoli", LXX (1959), pp. 144-202; I mercanti catalani e l'espansione della Corona d'Aragona nel secolo XV, Napoli, Liguori, 1972; y La 'Corona d'Aragona' e il Mediterraneo en "Atti del IX Congresso di Storia della Corona d"Aragona" (Napoli, 11-15 aprile 1973), Nápoles, 1978, I, pp. 301-331.

${ }^{16}$ Corrado ZEDDA, La piazza commerciale di Cagliari tra Barcellona e Napoli nel XV secolo, "Estudis Històrics i Documents dels Arxius de Protocols", XV (1997), pp. 77-92; y Cagliari: un porto commerciale nel Mediterraneo del Quattrocento, Roma-Napoli, 2001.

${ }^{17}$ Sergio TOGNETTI, Il ruolo della Sardegna nel commercio mediterraneo del Quattrocento. Alcune considerazioni sulla base di fonti toscane, "Archivio Storico Italiano", anno CLXIII, 2005 , n. 603 , pp. $87-131$. 
(1468-1484), Michele Leytago (1484-1487) y Giovanni Carnicer (1498-1511). Todos estos protocolos forman parte del fondo denominado "Antico Archivio Regio”, procedentes de la serie de 'Tappa di insinuazione di Cagliari', sección segunda correspondiente a actos notariales sueltos ${ }^{18}$.

Las noticias contenidas en la documentación notarial cagliaritana son diversas y de distinto género. De esta manera, podemos encontrar desde el estudio del tráfico con los países del Mediterráneo a aquellos con el interior; de las relaciones recíprocas entre mercaderes, artesanos, pastores y campesinos, a las relaciones con elementos instalados en la isla o forasteros; de las grandes transacciones a las pequeñas deudas; desde bodas hasta peleas. Todo contribuye a generar una visión de la vida cotidiana de Cagliari en el Cuatrocientos, de gran interés para el estudio de los aspectos sociales, económicos, culturales y religiosos, por lo que es necesario seleccionar y agrupar el material según el empleo que se quiere hacer.

La intención primordial de este artículo se basa en llevar a cabo una primera cala-cata o muestreo documental utilizando los protocolos como fuente básica y de primaria importancia para el estudio que enlaza aspectos relacionados con la presencia de foráneos (independientemente de ser o no residentes en Cagliari), centrando la atención concretamente en algunos valencianos y aragoneses, que emergen sobre todo a través de unos determinados tipos de documentos, ya sea por la localización de noticias biográficas o bien por la reconstrucción del ambiente familiar y privado de los personajes considerados: procuras, letras de cambio, seguros marítimos, compraventas, deudas, testamentos..., un amplio abanico de variedades documentales que se clasifican según la naturaleza, el carácter o la intención propia de cada acto notarial.

La escritura que caracteriza estos actos notariales se trata casi siempre de una gótica minúscula cursiva redactada en lengua latina, con la salvedad de unos pocos documentos escritos en el respectivo idioma local, el catalán. No obstante, nos encontramos con el hecho de que muchos actos son bilingües, es decir, escritos generalmente la parte formulística en latín y la documentaria con terminaciones en catalán. Ello denota el inexorable alejamiento de la costumbre pisana y genovesa que hasta ahora había guiado el quehacer de los notarios sardos, porque desde la llegada en Cerdeña de los catalano-aragoneses en 1323-1326 y su inmediata anexión a la Corona de Aragón hizo que a partir de entonces y progresivamente los notarios ibéricos poseyeran una cultura y formación jurídica de tradición eminentemente catalana tal y como exhiben inequívocamente los formularios, signos y suscripciones notariales del momento, componentes imprescindibles para la validación del documento.

\footnotetext{
${ }^{18}$ Véase Silvio LIPPI, Inventario del Regio Archivio di Stato di Cagliari e notizie delle carte conservate nei più notevoli archivi comunali, vescovili e capitolari della Sardegna, Cagliari, Deputazione di Storia Patria per la Sardegna, 1902, pp. 63-83.
} 
La mayoría de las fuentes notariales permanecen inéditas, aunque son varias las incursiones que se han realizado sobre ellas ${ }^{19}$. Contamos con varios trabajos, incluso tesis de licenciatura, que se pueden consultar en la misma biblioteca del Archivo de Estado de Cagliari. Por orden cronológico de la actuación de los notarios son las siguientes: el trabajo de Gabriella Olla Repetto $^{20}$ sobre Pietro Baster; así como el estudio de Maria Bonaria Urban ${ }^{21}$ y las tesis de Maria Adelaide Ferralis ${ }^{22}$ y Mariella Marrocu ${ }^{23}$ para Giovanni Garau; la tesis de Marcella Pau ${ }^{24}$ para Stefano Daranda; la de Gianna Ghiani ${ }^{25}$ para Pietro Steve; la de Silvana Pisano ${ }^{26}$ para Pietro Durante; las más numerosas de Giuseppina $\mathrm{Cau}^{27}$, Caterina Sanciu ${ }^{28}$, Maria Bonaria Floris ${ }^{29}$,

${ }^{19}$ En esta dirección merece hacer alusión a algunos catálogos de exposiciones que han indagado sobre este fondo notarial: Vestigia Vetustatum. Documenti manoscritti e libri a stampa in Sardegna dal XIV al XVI secolo. Fonti d'archivio: testimonianze ed ipotesi, Cagliari, 1984,2 vols; Cultura quattro-cinquecentesca in Sardegna. Retabli restaurati e documenti, Cagliari, 1985 ; y La Corona d'Aragona: un patrimonio comune per Italia e Spagna (secc. XIV-XV), Cagliari, 1989.

${ }^{20}$ G. Olla RePETto, Notai sardi del XV secolo: Pietro Baster en "Studi Storici e Giuridici in onore di Antonio Era", Padova, 1963, pp. 269-297.

${ }^{21}$ Maria Bonaria URBAN, Joan Guerau, maestro razionale del regno di Sardegna (1459-1474), “Medioevo. Saggi e Rassegne», 21 (1996), pp. 147-197. Nacido de padres sardos en el apéndice de Villanova, el 22 de marzo de 1441 obtuvo el nombramiento de notario. Primeramente ocupó el cargo de lugarteniente del procurador real como se muestra en un documento localizado en la ciudad de Sassari el 18 de mayo de 1456 y, sucesivamente, desde 1459 fue también maestro racional del reino de Cerdeña, puestọ que ocupó hasta la mitad del año 1479; siendo además durante un trienio potestad de Sassari. De lo que se deriva una prestigiosa carrera de ascenso social, no separada de una sólida preparación cultural.

${ }^{22}$ Maria Adelaide FerRALIS, Il manoscritto N.C. 337 dell'Archivio di Stato di Cagliari. Minutario di Giovanni Garau (1441-1443), Tesi di laurea, Facoltà di Lettere e Filosofia de la Università degli Studi di Cagliari, dirigida por G. Brugnoli, año 1965-1966.

${ }^{23}$ Mariella MARROCU, Trascrizione e illustrazione di un minutario notarile del secolo XV. Notaio Giovanni Garau (1441-1459), Tesi di laurea de la Facoltà di Magistero de la Università degli Studi di Cagliari, dirigida por F. Artizzu, curso 1975-1976.

${ }^{24}$ Marcella PAU, Esame di un minutario notarile del secolo XV. Notaio Stefano Daranda (1448-1449), Tesi dị laurea de la Facoltà di Magistero de la Università degli Studi di Cagliari, dirigida por $\mathrm{F}$. Artizzu, año académico 1989-1990.

${ }^{25}$ Gianna GHIANI BARRANU, Alcuni atti notarili del secolo XV. Notaio Pietro Steve, Tesi di laurea de la Facoltà di Lettere e Filosofia de la Università degli Studi di Cagliari, dirigida por A. Boscolo, año académico 1958-1959.

${ }^{26}$ Silvana PISANO, Trascrizione ed illustrazione di un minutario notarile del secolo XV. Notaio. Pietro Durante, Tesi di laurea de la Facoltà di Lettere e Filosofia de la Università degli Studi di Cagliari, dirigida por F. Loddo Canepa, año académico 1955-1956.

${ }^{27}$ Giuseppina CAU, Una raccolta di atti notarili del secolo XV. Notaio Andrea Barbens, Tesi di laurea, Facoltà di Lettere e Filosofia de la Università degli Studi di Cagliari y el Istituto di Storia, dirigida por F. Loddo Canepa, año académico 1956-1957.

${ }^{28}$ Caterina SANCIU, Trascrizione e illustrazione di un Codice Ecclesiastico del XV secolo (1483-1484), Tesi di laurea de la Facoltà di Lettere e Filosofia de la Università degli Studi di Cagliari, dirigida por F. Loddo Canepa, año académico 1956-1957. Y sobre el mismo se puede consultar F. LODDO CANEPA, Un codice ecclesiastico cagliaritano del XV secolo en "Miscellanea in onore di Roberto Cessi", I, Roma, 1958, pp. 379-393.

${ }^{29}$ Maria Bonaria FLORIS, Trascrizione e illustrazione di un minutario notarile del secolo XV (Minutario di atti ecclesiastici dovuto ad A. Barbens), Tesi di laurea, Facoltà di Lettere de la Università degli Studi di Cagliari, dirigida por F. Artizzu, curso 1970-1971. 
Marilena Atzei ${ }^{30}$ y Simona Fuccella ${ }^{31}$ sobre Andrea Barbens; y, por último, la de Adriana Serri ${ }^{32}$ sobre Michele Leytago.

Con respecto a los propios notarios podemos decir que de los ocho analizados, tres son valencianos. Son los casos de Pere Esteve procedente de Játiva, Andreu Barbenç y Joan Carnicer, ambos originarios de Valencia. De al menos dos de ellos sabemos que se conservan fondos notariales en el Real Colegio Seminario del Corpus Christi, también conocido como Archivo de Protocolos del Patriarca de dicha ciudad, concretamente se sistematizan en cinco protocolos para Andreu (entre los años 1449 y 1466) y cuatro para Joan (entre 1469 y 1477$)^{33}$.

La situación política y económica particularmente favorable y las indudables dotes morales y culturales de ciertos notarios que, junto a mercaderes y juristas, conformaban una emergente clase burguesa dirigente, les permitieron emprender en el Reino de Cerdeña carreras prestigiosas, conquistando el monopolio de puestos clave en los despachos públicos y alcanzando posiciones sociales y económicas de elevado nivel. Entre los requisitos especiales para poder ejercitar la profesión de notario se encontraban: 1) haber superado la mayoría de edad fijada en 24 años, 2) haber cumplido estudios universitarios, 3) haber ejercitado la práctica por cinco años en un estudio notarial, a fin de demostrar el buen aprendizaje y conocimiento de la lengua latina y el saber redactar actos y, 4) haber superado el examen de idoneidad; a los que con posterioridad se añadió el tener que haber nacido en Cerdeña ${ }^{34}$.

Pero incidamos un poco más en el análisis prosopográfico de estos notarios ibéricos que trabajaron en Cagliari durante la segunda mitad del Cuatrocientos $^{35}$. Un significativo ejemplo fue Pietro Steve, hijo del que fuera Bernardo Esteve, también notario de la ciudad de Játiva, y de Juana. Desconocemos cuando se traslada a Cagliari, quizá acompañado de Jacobo Esteve, su hermano o pariente cercano, que también desempeñará la función de notario ${ }^{36}$. Lo cierto es que se queda huérfano en edad tempranísima,

\footnotetext{
${ }^{30}$ Marilena ATZEI, Il protocollo $n .1$ del notaio Andrea Barbens dell'Archivio di Stato di Cagliari, 1468-1469, Tesi di dottorato de la Facoltà di Lettere e Filosofia de la Università degli Studi di Cagliari, dirigida por L. D’Arienzo, año académico 1999-2000.

${ }^{31}$ Simona FuCCELla, I protocolli del notaio Andrea Barbens dell'Archivio di Stato di Cagliari (n. 2, 3, 4), años 1470-1473-1474), Corso di laurea in lettere de la Facoltà di Lettere e Filosofia de Cagliari, dirigido por L. D'Arienzo, año 1999-2000.

${ }^{32}$ Adriana SERRI, Esame di un minutario notarile del secolo XV. Notaio Michele Leytago (1484-1487), Tesi di laurea de la Facoltà di Magistero de la Università degli Studi di Cagliari, dirigida por F. Artizzu, año académico 1989-1990.

${ }^{33}$ Consultar las fuentes archivísticas disponibles en el Apéndice.

${ }^{34}$ Para conocer una presentación general del notariado en Cerdeña recomendamos la lectura del antiguo y ya superado trabajo de P10 CANEPA, Il notariato in Sardegna, "Studi Sardi", anno II, fasc. II, XV (1936), pp. 61-137.

${ }^{35}$ Olivetta SCHENA, Notai iberici a Cagliari nel XV secolo: proposte per uno studio prosopografico en La Corona Catalanoaragonesa i el seu entorn mediterrani a la Baixa Edat Mitjana "Actes del Seminari celebrat a Barcelona, novembre 2003", Barcelona, Institució Milà i Fontanals - Departament d'Estudis Medievals, 2005, pp. 395-412.

${ }^{36}$ Este tal Giacomo Steve aparece como testigo en un acto de composición de un litigio redactado por Pere Steve el 15 de febrero de 1457, t. $18 \mathrm{r}$.
} 
motivo que le condujo a seguir los estudios tutorizado por su padastro Fernando Guill, que casó en segundas nupcias con su madre ahora trasladada a la ciudad de Alicante, como resulta de un acto de procura donde se dice que Guill post ipsum Deum immortalem aprimis meetatis cunabilis me in litteris eruditi faciendo educavit et ut amore paterno usque ad etatem provectam et eius dies extremos honoribus et arte vivendi me instituit ${ }^{37}$. En este mismo acto notarial se nos indica que Pietro Steve nombra procurador a Giacomo Guill de Alicante, hermano de su difunto padastro Fernando, para la redacción de los capítulos matrimoniales y la celebración de la boda entre él y Caterina Franch, hija de Costanza y de Giacomo, mercader de Alicante. Asimismo, y parecido a lo que veremos que ocurrirá con los mercaderes, incluso residiendo en Cagliari, no se interrumpieron las relaciones con la madre patria, como demuestra el revelador caso de Pietro Steve que, al momento de casarse, prefirió la boda con una conterránea, probablemente combinada por los parientes españoles, fruto de un hábil y calculada estrategia de política matrimonial. Al parecer Pietro consigue ser nombrado notario por derecho de sucesión, como una de las varias vías que se podían seguir para alcanzar tal profesión $^{38}$. Parece, además, que desarrolla una notable actividad y que está muy solicitado; de hecho, contaba con un sustituto que era el notario Gabriel Serra. Con todo lo dicho hasta ahora, se puede afirmar que ejercitaba la profesión liberal en Cagliari ya desde 1454, como atestiguan sus propios protocolos, pero el nombramiento soberano que lo autoriza a ejercer en todos los territorios de la Corona de Aragón se remonta al 2 de junio de $1457^{39}$. No es improbable que anteriormente a esta fecha poseyera el permiso de notario de la ciudad, otorgado por una autoridad delegada por el soberano, por ejemplo del vicario, coadyuvado por una comisión compuesta de jueces y notarios. El título de notario regio le vino, en cambio, otorgado en 1457 y de este momento pudo desarrollar actos no sólo en el territorio isleño sino también en otras plazas, por ejemplo en Nápoles, donde está presente ya en $1458^{40}$. Se podría, pues, distinguir al menos en hipótesis que en la Cerdeña del siglo XV, al igual que acontecía en la ciudad condal ya desde el Trescientos, existieran dos categorías de notarios: los notarios públicos de la ciudad, que ejercieron el oficio exclusivamente entre privados y en el ámbito del derecho privado; y los notarios regios, que revistieron las escribanías de los despachos de la administración regia y cívica, a los que no fue vetado el ejercicio de la libre profesión.

Por su parte, Andrea Barbens, nativo de Valencia, fue notario público y escribano de la Curia arzobispal, que operó en la ciudad de Cagliari desde 1468 a 1483. El Signum Tabellionis de un pergamino escrito en latín y

\footnotetext{
${ }^{37}$ Archivio di Stato di Cagliari (en adelante ASC), Atti Notarili Sciolti (ANS), Tappa di Cagliari, Notario: Steve, 1458-VII-28, ff. 48r-50v.

${ }^{38}$ Véase P. CANEPA, Il notariato in Sardegna, citado, p. 38.

${ }^{39}$ La Corona d'Aragona: un patrimonio comune, citado, a cargo de G. Olla RePETTO, Milán, 1989, ficha 471, p. 301.

${ }^{40} \mathrm{G}$. Olla RePeTto, La società cagliaritana, citado, p. 23, nota 14.
} 
estipulado en Cagliari el 22 de noviembre de 1486, conservado en el Archivo Amat de San Filippo, nos certifica personalmente su procedencia valenciana ${ }^{41}$. La clientela de la quincena de protocolos del Archivo de Estado de Cagliari redactados por él está constituida en su mayor parte por mercaderes catalanes, y entre sus actos notariales sobresalen las procuras, compraventas, constituciones de dote y aseguraciones.

También la actividad del notario Giovanni Carniçer se presta, a nuestro juicio, a interesantes consideraciones. De él hemos inducido que pudo maniobrar a tres bandas, puesto que, primeramente, lo encontramos actuando como notario de Valencia desde 1469 a 1477. Después figura como escribano de Maella (Zaragoza), firmando como testigo en un acta notarial redactada por Andrea Barbens ${ }^{42}$; suponemos que estaría familiarizado con Domingo Carnicer, pariente suyo al que encontramos ejerciendo también como notario del mismo lugar aragonés en un documento fechado en 1485 y custodiado en el Archivo Histórico de Protocolos de Zaragoza ${ }^{43}$. Para, finalmente, ejercer su oficio en Cagliari a partir de 1498 hasta bien entrado el año 1511. En cuanto a la naturaleza de sus actos tan solo se ha conservado la redacción de sus testamentos, en concreto ocho pertenecientes al único fragmento de protocolo signado con el número de volumen $118^{44}$.

Aparte de los tres citados, sabemos que hubo muchos más notarios que fueron ibéricos de nacimiento, como Pietro o Pere Baster ${ }^{45}$, alias de la tierra de Nagella, autoritate regia notarius publicus per totam terram et dominacionem illustrissimi domini Aragonum regis, que fijó su residencia en el Castillo de Cagliari, el cual ya había iniciado su actividad en el ámbito de la escribanía de los puestos de la administración ciudadana interviniendo desde el año 1419 en la redacción de los actos del 'Comune' en calidad de testigo o de rogatario, y revistiendo en 1422 el cargo de regente de la escribanía del vicario $^{46}$. Y tantos otros de quienes no se ha conservado documentación pero que se encontraban operando en la capital isleña, como son los casos de Jaume Cervero (de Játiva), Miguel Çigar (de Gerona) y Paolo Ludovico Berart (de Mallorca $)^{47}$.

\footnotetext{
${ }^{41}$ Un catálogo de los principales signos de notarios operantes en el reino sardo y también en otros territorios de la Corona de Aragón durante el tracto temporal que va de los siglos XV al XVIII puede verse en Vincenzo AMAT DI SAN FILIPPO y Marina VALDÉS CARBONI, Segni tabellionali in Sardegna dal 1409 al 1786, Cagliari, 1983.

${ }^{42}$ ASC, ANS, Barbens X, 1477-VII-22, f. 8v.

${ }^{43}$ AHPZ, Notario: Domingo Carnicer, Sign. 31.

${ }^{44} \mathrm{De}$ entre ellos nos interesa principalmente el testamento dejado por Antonio Durrea, nativo de la ciudad de Daroca, pero casado y domiciliado en la ciudad de Cagliari (ASC, ANS, Carnicer, 1498-III-9, ff. $4 \mathrm{v}-5 \mathrm{v}$ ).

${ }^{45}$ Véase Josep Gramunt, Los linajes catalanes en Cerdeña, Barcelona, 1958, voz Baster.

${ }^{46} \mathrm{G}$. Olla RePETTO, Notai sardi, citado, pp. 271-275.

${ }^{47}$ Encomendamos la consulta del artículo de Anna Maria OlIVA y Olivetta SCHENA, Il Regno di Sardegna tra Spagna ed Italia nel Quattrocento. Cultura e società: alcune riflessioni en Descubrir el Levante por el Poniente. "I viaggi e le esplorazioni attraverso le collezioni della Biblioteca Universitaria di Cagliari "Convegno Internazionale di Studi" (Villanovaforru, 1 diciembre 2001), a cura di Luciano GALLINARI, Cagliari, 2002, pp. 101-134, en concreto las relativas al notariado son 130-133.
} 
Poco más podemos añadir, salvo que el texto de todos estos minutarios notariales provee útiles elementos en cuánto la estratificación social y las condiciones político-económicas de la sociedad cagliaritana tardomedieval que de ella se traslucen, a través de la reconstrucción de la trama política, familiar y profesional de bastantes de sus integrantes, estando en directa relación con la posición geoestratégica que ocupaba la ciudad en la cuenca occidental del Mediterráneo.

\section{LAS RELACIONES COMERCIALES ENTRE VALENCIA Y CERDEÑA EN EL SIGLO XV}

La relación económica entre ambas zonas ha sido considerada desde la óptica que emana del laboratorio privilegiado que proporcionan las fuentes valencianas por parte de Enrique Cruselles ${ }^{48}$, Jacqueline Guiral ${ }^{49}$, José Hinojosa $^{50}$, Emilia Salvador ${ }^{51}$ o David Igual ${ }^{52}$, entre otros. En consenso más o menos acorde, todos los autores coinciden en apuntar que, pese a que hayan empleado registros fiscales y libros notariales que abarcan un arco cronológico que abarca desde el último cuarto del siglo $\mathrm{XV}$, los contactos bilaterales e influencias mutuas entre Valencia y Cerdeña fueron una realidad al menos desde principios del Cuatrocientos, e incluso anteriormente vinieron facilitados por la concesión de una serie de privilegios dados ya en el XIV, que estipulaban varias libertades comerciales y fiscales que resultaban beneficiosos para las dos partes ${ }^{53}$. En aquel tiempo, la isla se comportaba fundamentalmente como zona suministradora de importación de cereales y otras materias primas (queso y pasta) para asegurar el normal aprovisionamiento de ciertos productos, pero también formaba parte de un circuito integrado de exportación que funcionaba como lugar de mercado buscando dar

\footnotetext{
${ }^{48}$ Enrique CRUSELlES GóMEZ, Comercio y mercado en tiempo de crisis (Los mercaderes valencianos y su.Mediterráneo frente a la época de los Descubrimientos), trabajo de investigación inédito, Valencia, 1991. El autor estudia concretamente seis protocolos pertenecientes a los notarios Jaume Salvador y Guillem Ramon Florença, conservados para el período 1488-1520, que en realidad son libros especializados en la redacción de negocios marítimos asegurativos.

${ }^{49}$ Jacqueline GUIRAL-HADZIIOSSIF, Valencia, puerto mediterráneo en el siglo XV (1410-1525), Valencia, 1989, especialmente pp. 35-36, 256, 262, 340-341, 350 y 381-384.

${ }^{50}$ José Hinojosa MonTalvo, Los contactos comerciales entre Valencia y Cerdeña durante el siglo XV en "Atti del XIV Congresso di Storia della Corona d'Aragona" (Sassari-Alghero 1990), vol. III, Sassari, Carlo Delfino, 1996, pp. 503-526.

${ }^{51}$ Emilia SALVADOR ESTEBAN, Aproximación al tráfico marítimo entre la isla de Cerdeña y la ciudad de Valencia en el siglo XVI en "Atti del XIV Congresso di Storia della Corona d'Aragona", vol. II, tomo II, Sassari, 1995, pp. 769-787.

${ }^{52}$ David Igual LuIS, Valencia e Italia en el siglo XV. Rutas, mercados y hombres de negocios en el espacio económico del Mediterráneo occidental, Castellón, 1998, pp. 34-35, 52, 310, 316, 411. Y más específicamente Comercio y operadores económicos entre Valencia y Cerdeña durante el reinado de los Reyes Católicos en Sardegna, Spagna, Mediterraneo, Atlantico dai Re Cattolici al Secolo d'Oro "Convegno Internazionale di Studi Storici”, a cargo de B. Anatra y G. Murgia, Roma, 2004, pp. 33-56.

${ }^{53}$ Aureum opus regalium privilegiorum civitatis et regni Valentie cum historia cristianissimi Regis. Jacobi ipsius primi conquistatoris, Valencia, Ayuntamiento, 1999, pp. 204-206 (privilegio de Jaime II, n CXI, fechado el 1 marzo de 1322) y p. 255 (privilegio de Aifonso II, $\mathrm{n}$ XXXV, el 25 enero de 1332).
} 
salida a los excedentes de determinados productos manufactureros (paños de mediana o baja calidad) o semi-elaborados (vino y cerámica) realizados en la capital del Turia.

Si atendemos a la imagen dibujada por la geografía de los intercambios, hay que señalar una doble línea de navegación marítima que partía de las costas valencianas ${ }^{54}$ : la articulada alrededor del comercio directo con la isla y la organizada sirviendo de escala obligatoria de apoyo o intermediación en la clásica "ruta de las islas" de la Corona de Aragón, que unía el litoral ibérico con las Baleares (en especial Ibiza, para los cargamentos de sal), Cerdeña y Sicilia, y sólo en ocasiones se proyectaba hacia otras partes de la Italia peninsular ${ }^{55}$. El substancial elemento a considerar sería la configuración de las tierras sardas y también mallorquinas como punta de lanza para el desplazamiento de las naves valencianas en los mercados mediterráneos, donde perfectamente tienen cabida las exportaciones e importaciones sículosardas ${ }^{56}$.

Antes que nada, hay que recordar que Cagliari, además de estar inserto en las corrientes de tráfico comercial del Mediterráneo, en particular respeto al comercio directo mantenido con el Levante, y desde donde podían incluso dirigirse con facilidad a las plazas norteafricanas occidentales y orientales; a mediados del Cuatrocientos fue introducido, según un preciso mecanismo de política económica planteado por Alfonso el Magnánimo, en la ruta atlántica ${ }^{57}$ que conducía desde el norte de Europa hasta Flandes e Inglaterra - un amplio espacio que comprendía desde Portugal hasta el Mar del Norte-, lo cual le permitió integrarse en el sistema de redes de negocios internacionales más complejo de la época.

La posición geográfica de Cagliari con su desfiladero natural abierto al Mediterráneo, convierte a la ciudad en un ir y venir de gentes de diversas nacionalidades: catalanes, valencianos, aragoneses, mallorquines, italianos,

\footnotetext{
${ }^{54}$ Tres trabajos donde se dispone un análisis de los flujos de comercio mediante el examen de las rutas marítimas que giraban en torno a Valencia son el de Paulino IRADIEL MURUGARREN, El siglo de Oro del comercio valenciano en I. AGUILAR CIVERA (coord.), El comercio y el Mediterráneo. Valencia y la cultura del mar, Valencia, Generalitat, 2006, pp. 111-129; más los dos de D. IGUAL LUIS, Itinerarios comerciales en el espacio meridional mediterráneo de la Baja Edad Media en Itinerarios medievales e identidad hispánica "Actas XXVII Semana de Estudios Medievales de Estella", Pamplona, 2001, pp. 113-158; y Non ha portto alcuno, ma solo spiaggia. La actividad martítima valenciana en él siglo XV en Les ciutats portuàries en el proces de desenyolupament econòmic italià $i$ espanyol entre la Edat Mitjana i la Edat Moderna (1400-1600) "Seminario Internacional" (Valencia, noviembre 2002), actas en prensa.

${ }^{55}$ Véase M. DEL TREPPO, Els mercaders catalans $i$ l'expansió de la corona catalanoaragonesa al segle XV, Barcelona, 1976, pp. 15-20; y E. CRUSELLES, Los mercaderes de Valencia en la Edad Media (1380-1450), Lérida, 2001, pp. 33-34.

${ }^{56}$ Una breve historia de los contactos y relaciones entre Sicilia y Cerdeña durante la Baja Edad Media puede encontrarse en C. ZEDDA, La Sardegna nel'400: un crocevia sulla rotta del Levante en "Actas del XVIII Congreso de Historia de la Corona de Aragón" (Valencia 2004), Valencia, 2005, vol. II, pp. 1351-1368.

${ }^{57}$ Testimonia tales relaciones la presencia en Cerdeña de hombres provenientes del mundo atlántico: G. OLLA REPETTO; Giuseppina CATANI, Cagliari e il mondo atlantico del 400' "Rassegna degli Archivi di Stato", XLVIII/3 (1988), pp. 675-685, editado también en "Actas del y Cecilia TASCA, Portoghesi in Sardegna nell'età delle scoperte, "Archivio Storico Sardo", XXXVII (1992), pp. 145-180.
} 
pero también de hombres provenientes del Atlántico, como castellanos, portugueses, vizcaínos, flamencos e ingleses. Cagliari se convierte, pues, para bien o para mal y durante muchos siglos en la principal puerta de entrada a Cerdeña, importante ciudad de acceso y puerto comercial ubicado al sur de la isla frente al golfo al que da nombre como nudo de reordenación del tráfico marítimo, a la vez que sede de múltiples intereses políticos, estratégicos y económicos $^{58}$, reafirmando su condición privilegiada de enlace y encrucijada de intercambios.

Los notarios, por supuesto, daban fe pública de las transacciones y acciones económicas, aunque eran pocos los que podían recibir tal título, porque lo habitual era que recogieran los pequeños préstamos, ordinariamente en especie, que permitían salvar una mala situación, los modestos "depósitos" que solucionaban una necesidad, o las pequeñas compras y ventas de excedentes. Sin embargo, las escrituras notariales consultadas también recogen instrumentos de procura, estipulación de deudas o créditos, contratación de fletamentos o nòlits (arrendamiento de navíos para transportar mercancías de un puerto a otro) y otros asuntos de varia naturaleza, a los que habría que unir la intensidad del tráfico financiero desarrollado mediante la recurrencia al más costoso mercado de letras de cambio enviadas sobre todo de Cerdeña a Valencia ${ }^{59}$. La procura fue una práctica usual cuando no fue posible seguir personalmente todo el volumen de negocios, sea por los múltiples intereses, sea por el hecho que los negocios se desarrollaron sobre plazas diferentes, o en aquellas relativamente vecinas de la isla, o bien en las de ultramar.

Entre la documentación inédita consultada están bien representados los instrumentos procuratorios para los mercaderes que obraron entre Barcelona, Mallorca y Cagliari, los que fueron luego la mayoría de los operadores en la plaza sarda, aunque también, y de modo particular, fue significativa la presencia valenciana. Generalmente se trataba de un factor o una persona de confianza que atendía los asuntos del gran o pequeño mercader, como es el caso de Pere Fortuny que a menudo comparece como procurador de mercaderes sardos y valencianos en la isla, cuyo hermano, Guillermo, habitante de Gandía, le hizo paralelamente procurador para mantener sus negocios en aquel territorio ${ }^{60}$. Por otra parte, la familia de Jaume Bertran,

${ }^{58}$ Resulta interesante la lectura de Alessandra STANGANELLI, L'identità della isole attraverso le identità della città. Cagliari nel rapporto Regno sardo-Corona d'Aragona en "Mediterránea. Isole nella storia", I-2 (gen.-ago. 2003), Anno XV, pp. 161-173.

${ }^{59} \mathrm{D}$. IGUAL LUIS, El mercado cambiario entre Valencia y Cerdeña (1460-1500). Dinero y comercio en el Mediterráneo comunicación presentada al "XVIII Congreso de Historia de la Corona de Aragón" (Valencia, 2004), aunque no figura en sus dos volúmenes de actas publicadas en esa misma ciudad el año 2005, puesto que no llegó a tiempo la redacción definitiva. En el folio resumen de su propuesta ya se mạrcaba el objetivọ de pretender analizar las características de esta corriente de mercado cambiario sardo-valenciano, remarcando que las letras examinadas especialmente en las fuentes notariales valencianas han permitido deducir por el momento varias ideas acerca de su evolución temporal, lugares de emisión, sumas monetarias implicadas y cotizaciones, técnica con la que se elaboraban los cambios y sus protagonistas humanos, entre los que subraya los apellidos Adret, Alcanyís y Navarro (entre los operadores asentados en Valencia) o Allepús, Besalú, Carnisser y Gessa (entre los establecidos en Cerdeña).

${ }^{60}$ ASC, ANS, Garau I, 1443-V-20, ff. 64 r-v. 
también mercader y procurador valenciano, actúa en 1443 , cuando junto a su abuelo homónimo, al padre, Johan Bertran y a Jaume des Pla, nombran su procurador al mercader cagliaritano Bernat Montallans, quien fue encargado de cobrar en Cerdeña varios créditos, entre los cuales figura uno del mercader Guillermo Nicolás ${ }^{61}$.

Se ha visto que muchos procuradores actuaron sobre el eje de Cagliari-Valencia con el fin de despachar los negocios mantenidos entre ambas plazas. Los mercaderes cagliaritanos Guillermo Nicolás y Pere Fortuny, declararon haber recibido de Antonio de Sena, vizconde de Sanluri, las sumas debidas por algunas de sus acciones, como la sostenida con Jaume Bonfill $^{62}$.

A tenor del análisis de estos actos emerge cómo fue difundida entre los mercaderes que vivieron en la madre patria y tuvieron intereses económicos en Cagliari, la costumbre de nombrar para la gestión de los propios asuntos de los representantes entre los mercaderes locales. Es este el caso del mercader de Valencia, Vicente Aznar, que nombra su procurador general al mercader cagliaritano Álvaro Gallego, para la recuperación de créditos y otras cuentas, para la presentación de letras de cambio y para efectuar, en su nombre, cualquier operación comercial ${ }^{63}$. De la misma forma, el 12 de junio de 1455, Johan Pertusa, mercader habitante en Cagliari, nombró en lugar de Lorenç Soler y Luis Soler, mercaderes de Valencia, sus procuradores para percibir de Martín Pons, ciudadano de Valencia, y de otros deudores, cada uno de los créditos por él alegado bajo la forma de mercancías, dinero, letras de cambio y todo cuanto le esperaba, que por cuanto concernía a Martín Pons, la deuda ascendía a 40 libras valencianas ${ }^{64}$. Un mes después, el 11 de julio, Johan Arnald, oriundo del reino de Valencia, nombraba procurador suyo a Pietro Serra para el cobro de todos sus créditos en la isla. Entre los testimonios figura el mismo Pedro de Calatayud, regente en la procuración real del Reino de Cerdeña ${ }^{65}$. De estos últimos documentos se intuyen también las fuertes conexiones que unieron en la mitad de la decimoquinta centuria numerosas familias cagliaritanas, sean grandes o pequeñas, al mundo comercial valenciano, por entonces en plena fase de crecimiento.

Otro caso interesante se presenta con una procura específica que no atañe a la recuperación de bienes o sumas de dinero, sino a una viuda de Valencia llamada Úrsula (esposa que fue del difunto Antonio Pellegrini, agricultor de Valencia), casada en segundas nupcias con otro agricultor valenciano Jacobo Bono, que nombra su procurador al conciudadano Antonio Salvat para que se preocupe de liberar a su hija Francisca de aquel que la

\footnotetext{
${ }^{61}$ Garau I, 1443-V-31, f. 65 v.

${ }^{62}$ Ibidem, 1441-XII-23, ff. 16 r-v.

${ }^{63}$ Barbens II, 1470-VI-16, ff. $14 \mathrm{v}-15 \mathrm{v}$.

${ }^{64}$ Garau II, ff. $124 \mathrm{v}-125 \mathrm{r}$.

${ }^{65}$ Ibidem, 1455-VII-11, f. 139 r.
} 
tuviera prisionera ${ }^{66}$. En otra cláusula dispositiva la misma Úrsula nombra a otro procurador, Ludovico Pérez, espartero valenciano, esta vez sí con el fin de recuperar, rescatándolos de los que los detienen en prenda, una serie de bienes que la mujer ha dejado en la ciudad de Valencia. Del documento -que se abre y cierra en latín, aunque la parte relativa al elenco de bienes esté en catalán, así como el nombre o la descripción de las personas que los tienen en posesión-, se puede intuir que Úrsula había sido obligada a empeñar tales bienes a causa de atravesar un momento difícil y que ahora, restablecida la propia hacienda, quería volverlos a recuperar ${ }^{67}$

Además de las cartas de poder o procuraciones que se emplearon en asuntos muy variados tanto personales como de carácter comercial, contamos otro tipo de asociaciones, como los negocios realizados mancomunadamente, más frecuentes incluso que las compañías; las comandas mercantiles (la entrega de capital de un individuo a otro para lucrarse con el comercio); y aquellas sociedades que exigían continuidad en el tiempo, como son las compañías mercantiles que operan en esta ruta con unas estrategias bien claras (normalmente de corta duración y que tenían un claro componente familiar o de pocos socios). Para este último caso, tenemos información sobre la formación de una de estas compañías catalano-valenciana que tuvo intereses en Cerdeña y cuyos capítulos fueron concordados entre Anlaguer Limes, patrón de una carabela llamada Santa María de Bonaria, de una parte, y Pere Pujol, patrón de otra llamada San Antonio y Magdalena, de la otra, con el fin de conducir juntos en el viaje que debían realizar hacia el Levante. Más adelante viene establecido que Anlaguer Limes, una vez llegado a Valencia con la carabela habría hecho conducir la embarcación desde aquella ciudad a Barcelona y de allí habría viajado con la carabela de Pere Pujol. La primera etapa habría sido Mallorca, por lo tanto la compañía habría hecho parada en Cagliari, desde donde irían luego a Nápoles, para continuar hasta Palermo y por fin llegar a Mesina. Éste mismo habría sido el trayecto que la compañía habría cumplido de vuelta: lo dit Anlaguer Limes, iunt que sia en Valencia ab la dita sua calavera, fara cridar la dita calavera de Valencia en Barchinona e de Barchinona partint en conserva ab la calavera del dit Pere Pujol, anant en Mallorcha, e de Mallorcha en Caller, e de Caller en Napols, e de Napols en Palerm en Meçina, tornant per la dita scala mari ${ }^{68}$.

Como técnica financiera debemos reparar en la importancia otorgada a la letra de cambio, un cómodo instrumento con el que el mercader o el hombre de negocios en general evitaban llevarse consigo, durante sus viajes, embarazosas y apetecibles sumas de dinero. La letra de cambio pudo ser declarada por el negociador con acto notarial, y era ésta, eventualmente, la única ocasión en que se acudía ante el notario. Un ejemplo de las estrechas relaciones entre la plaza cagliaritana y la valenciana se encuentra en un

\footnotetext{
${ }^{66}$ Barbens I, 1468-X-8, f. 3 r.

${ }^{67}$ Ibidem, 1468-XI-28, ff. 9 v - 10 r

${ }^{68}$ Garau II, 1455-VII, ff. $144 \mathrm{v}-145 \mathrm{r}$.
} 
documento datado el 31 de noviembre de 1442, en el que Jaume Costells, ciudadano valenciano ahora residente en Cagliari, nombra al notario barcelonés Johan de Olivella su procurador para el cobro de algunos de sus créditos y, en particular, 60 ducados de Checho de [...] y Oguitzo de la Casa, mercader de Florencia operante en la ciudad de Gaeta, como resulta de una letra de cambio de Checho de Johan, florentino, de éstos enviada al Costells a Valencia ${ }^{69}$. Al igual que, ante la presencia del notario Pietro Durante, Giovanni Dedoni hace una letra de cambio dirigida a García Navarro, de Valencia, para que pague al señor Dionisio Rosell 230 liras prometiendo a Giovanni Vaccarella, empeñado como él en dicha letra, que en el caso de que el cambio no fuera efectuado tendría la facultad de volver a cambiar cuantas veces quisiera ${ }^{70}$. Unos días más tarde, se nos informa que el mercader Juan Bertrán pide a su procurador Berengario Çaplana otra letra de cambio, por la cual le pagará 178 libras y 5 sueldos en moneda cagliaritana por valor de 55 libras reales valencianas que había recibido del tal García Navarro ${ }^{71}$.

Aparentemente interesantes son también los contratos de venta de barcos estipulados por algunos mercaderes no cagliaritanos pero residentes en la ciudad. Es ilustrativo el ejemplo de Bartolomé Martín, ciudadano valenciano por entonces residente en Cagliari, quien el 20 de noviembre de 1442, vendía al mercader florentino Stefano de Taddeo d'Ambrosio su ballenero, llamado Santa María, completo de todo el instrumental y con capacidad para 80 barriles, anclado en el interior de la empalizada del puerto de Cagliari por el precio de 240 florines de oro de Aragón (teniendo en cuenta que en este período un florín era equivalente a 27 sueldos ${ }^{72}$. Un año después, el 24 de abril de 1443, y de modo similar, Enneto Dartiaga, patrón de otro ballenero castellano llamado Santa María y también anclado en el mismo puerto, reconoce al valenciano Blasco (de quien no se indica el nombre, sólo que es dierum menore), hijo del mercader valenciano Bartolomé Blasco, conductor de su ballenero, haber recibido por parte del padre, de común acuerdo, 100 florines correspondientes a 110 liras de alfonsinos cagliaritanos como plazo por el alquiler del ballenero realizado por Bartolomé Blasco ${ }^{73}$.

Con un primer documento, estipulado por el notario Pere Steve directamente sobre la trirremos Santa Cristina del patrón, Francesco de Peri nombraba su procurador a Antoni d'Almevara, escribano de la embarcación, para comparecer en su nombre frente a cualquier oficial regio o de otra competencia en cualquier sitio. Como testigos comparecieron dos marineros del bastimento: Pere Devits, natural de Valencia y Nicolás Martí, natural de Mallorca. En virtud de su procuración Antoni d'Almevara renovó, entonces, la invitación de Francesc Peri al vizconde de Gallano, Sancho Ruíz de Lihori,

\footnotetext{
${ }^{69}$ Garau I, 1442-XI-31, f. 48 v.

${ }^{70}$ Durante II, 1463-IX-2, ff. $103 \mathrm{r}-103 \mathrm{v}$.

${ }^{71}$ Ibidem, 1463-IX-28, f. 113 r.

${ }^{72}$ Garau I, 29 noviembre de 1442 , ff. 52 v-53 r.

${ }^{73}$ Ibidem, 1443-IV-24, f. 63 r.
} 
para embarcarse aquel mismo día en su embarcación. Hay que aludir a cómo en este documento el destino final del viaje no era solamente Cataluña sino también la ciudad de Valencia (in partis civitatis Valencie aut alis terris). Sabemos que el vizconde, por su parte, en un documento posterior, prometía embarcarse con todas sus pertenencias el día que fue establecido, puesto que al encontrarse en edad bastante avanzada suponemos que entraría dentro de sus planes regresar a la Península Ibérica para reposar con calma la vida tan agitada que había llevado ${ }^{74}$.

\section{Mercancías y productos comercializados}

Por lo que respecta a la naturaleza de las mercancías y productos que fueron objeto de intercambio entre la ciudad de Valencia y su reino adyacente y Cerdeña durante el siglo XV, hemos de destacar - como ya hemos apuntado sucintamente-, que desde la isla se exportaban las mercancías típicas de la producción local: queso, pieles, carne, vino, caballos, coral, productos del artesanado y apreciables cantidades de sal y de cereales. Mientras que del exterior llegaban los recursos locales que no producían o sólo producían en parte, o bien objetos que la artesanía local no realizaba y que el mercado isleño solicitaba: tejidos semiacabados, objetos de uso cotidiano o productos de lujo, especias y otras mercancías procedentes de los países ibéricos. Estos productos podían llegar a la isla de manera diferente: bien directamente desde los centros productores, cuando una expedición naval, por ejemplo volviendo del Levante hacía etapa en Cerdeña (hecho en todo caso poco frecuente), o por la redistribución sobre los mercados de la Corona de parte de los mercaderes que recuperaron las mercancías llevadas con las grandes expediciones del Levante, para luego redistribuirlas en los mercados locales o en aquellos no tocados por los grandes envíos ${ }^{75}$.

En cuanto al vino ${ }^{76}$, conservamos un documento que nos informa sobre el tráfico comercial mantenido conjuntamente entre judíos y cristianos. En septiembre de 1455, un mercader alicantino, Johan Prunisa, vendía a Andrés Aymerich y al judío Isaac Rinos, 110 botellas de vino bermejo: 50 botellas contenían vino de Alicante dulce y nuevo, mientras que las otras 60 restantes eran de vino de Montblanc, siempre de nueva cosecha, prometiendo cargar el vino sobre la primera fusta que partiera del puerto de Alicante rumbo a Cagliari, donde habrían descargado la mercancía. El precio establecido fue de 14 liras la botella, por un total de 150 liras de moneda cagliaritana ${ }^{77}$.

Es frecuente también acreditar la adquisición de paños originariamente valencianos, como aparece en un acto fechado el penúltimo día del mes de

\footnotetext{
${ }^{74}$ ASC, ANS, Steve, 1456-XII-24, ff. 16 r-v.

${ }^{75}$ Cfr. C. ZEDDA, Cagliari: un porto commerciale, citado, p. 99.

${ }^{76} \mathrm{G}$. Olla RePETTO, Vino a Cagliari nel sec. XV en Studi di geografia e storia in onore di Angela Terrosu Asole, a cura di L. D'Arienzo, Cagliari, 1996, pp. 529-539.

${ }^{77}$ ASC, ANS, Garau II, 1455-IX-12, f. 166 r.
} 
agosto de 1443, momento en el que Pere Dancona, mercader momentáneamente residente en Cagliari, reconoce deber a Martín Aymerich, famoso mercader cagliaritano, 112 liras de alfonsinos por la compra de cinco piezas de paño de lana de Valencia, al precio de 20 liras por paño, mientras que las restantes 12 liras le serían prestadas por Aymerich ${ }^{78}$. Como también lo es encontrar la venta de un carro de fideos (pasta), enviado por Masedo Meli a Valencia, y de otro carro de contenido similar encomendado por Jaume Garau, ciudadano de Barcelona ${ }^{79}$. Noticia que encontramos en un legado testamentario, al igual que en la última voluntad de Julián Scamado, mercader cagliaritano, donde dispone que a los ocho pobres que lleven su cuerpo y porten los cirios de su entierro "sien dades a cascu dells 2 canes de drap blau de Valencia bollat bo e sufficient" $"$.

Los seguros marítimos también evidencian el valor de ciertos productos. Así, por ejemplo, conocemos que un tal Giovanni Sobrabales, cirujano de Cagliari, asegura 5 cuartales de pasta y 52 quintales de queso, cargados en la barca del caballero Giordi Sureda, capitaneada por Bartolomé Negre. La cobertura asegurativa se extiende desde el momento en el que parte la mercancía desde el puerto de Cagliari, hasta su descarga en el puerto de destino, en este caso Valencia. Primeramente, tenemos constancia de que el mercader de Mallorca Gaspar Belioch aseguró otra carga de pasta y queso por cuenta de Martín Ferrer, también mallorquín, cargado en el barco del mismo Giordi Sureda. Ambos documentos fueron redactados el mismo día, lo que nos indica que la ruta a seguir, desde el momento en que la mercancía asegurada era cargada sobre la misma nave, debía hacer la primera etapa en Mallorca, para después proseguir en el camino hacia Valencia. La suma asegurada asciende a 100 liras por un premio asegurativo de 7 liras (cada lira equivale a 120 sueldos), a la par al $7 \%$ de la aseguración ${ }^{81}$.

A su vez, el ya nombrado Vicente Aznar asegura 18 botellas de vino y queso, cargado sobre el barco de Martín de Nues, de Vizcaya, capitaneado por él mismo. La cobertura asegurativa cubría desde el puerto de Cagliari hasta su destino en Valencia (haciendo antes una vez más escala en Mallorca). En este caso, la suma asegurativa asciende a 350 liras por un permiso de 15 liras, lo que supone el $4 \%$ del total asegurado ${ }^{82}$.

Destacamos, en último lugar, el hierro, que también estuvo presente en la estipulación de una deuda por la compra de seis quintales de este producto, que fueron vendidos por Pedro Canyelles a un tal Pedro Solanas por valor de 22 libras 10 sueldos, cuyo asunto fue recogido ante el tan nombrado testigo Vicente Aznar, mercader de Valencia ${ }^{83}$.

\footnotetext{
${ }^{78}$ Garau I, 1443-VIII-30, f. 72 r.

${ }^{79}$ Garau III, 1441-IX-24, f. 3 r.

${ }^{80}$ Garau III, 1459-IX-24, f. 25 v - 29 r.

${ }^{81}$ Barbens II, $1470-\mathrm{V}-24$, ff. $6 \mathrm{v}-8 \mathrm{r}$.

${ }^{82}$ Ibidem, 1470-VI-12, ff. $11 \mathrm{v}-13 \mathrm{r}$.

${ }^{83}$ Durante II, 1463-VI-2, f. 63 r.
} 
Dos premisas fundamentales caracterizan a estas variadas mercaderías: el ser originarias de la propia producción, ya sean productos agrarios o elaborados; o bien su adquisición condicionada por la importación desde Valencia, y que luego intuimos se redistribuirían especialmente por el interior de la isla. Además de la proximidad geográfica y la pertenencia a la misma confederación y conglomerado político, desde la perspectiva de producción, se ofrecían productos que se complementaban, principalmente por el contraste de sus tierras, brindando las condiciones favorables para que se produjera un movimiento comercial de cierta entidad.

\section{Crisol de mercaderes identificados}

Rastrear la realidad de los protagonistas que intervienen en las relaciones mercantiles resulta un tanto dificultoso, ya que su actividad, muy dinámica y poco sedentaria, hace que los restos escritos de la misma aparezcan muy dispersos. De ahí que sea valioso el número inconcreto de comerciantes que se ha podido extraer de la documentación notarial cotejada.

La complementariedad de intereses comerciales entre las plazas sarda y valenciana se trasladó al ámbito familiar al crearse una compleja trama de relaciones de parentesco sobre la que se sustentaba la gestión de las empresas mercantiles y de colaboración profesional que puede explicar la estancia más o menos duradera de los operadores valencianos y aragoneses en Cagliari. Más enrevesado todavía resulta desentrañar la enmarañada red familiar (densas tramas familiares nacidas de la naturalidad de los flujos migratorios y de los procesos de integración económica y social), la homonimia generacional y la endogamia profesional.

Por debajo de los grandes mercaderes con un amplio poder adquisitivo, que formarán parte de la oligarquía de carácter local de acuerdo a sus posibilidades y cuyo asentamiento sería permanente y bastante antiguo, existía un nutrido grupo de pequeños profesionales encargados de dinamizar y propiciar el intercambio a través de su participación variable y poco especializada, con cargamentos reducidos que raramente implicaban niveles altos de inversión.

Como señala David Igual, tres nombres surgen con frecuencia en las fuentes sobre todo valencianas: por un lado, Alfonso Sánchez, hombre de negocios y funcionario real, que estuvo presente en casi todas las vías euromediterráneas de relación de Valencia, gestionando cuantiosos fletes de embarcaciones y seguros; y por el otro, con una atención más especializada por Cerdeña, Gaspar Valentí y Miquel Alcanyís. Con los tres personajes entramos en lo que serían medianas o incluso grandes empresas locales a escala del mercado valenciano. El mismo Miquel Alcanyís, por ejemplo, creó hasta dos compañías con el fin de traficar bilateralmente de Valencia a Cerdeña, además de intervenir entre 1488-1520 en 30 seguros marítimos (algunos superiores a los 400 ducados), a través de los cuales reprodujo el 
típico esquema de intercambio de paños valencianos por el binomio característico de queso y pasta insulares ${ }^{84}$.

La relación sarda con el reino de Aragón está bastante más dirimida, aunque su presencia puede ser justificada gracias a una investigación que todavía está pendiente de realizar, como es el del análisis e identificación de los linajes de familias aragonesas que pervivieron en Cerdeña tras la ocupación y conquista de Jaime II entre 1323-1324. Para la Cerdeña del Cuatrocientos faltan estudios sobre el papel político, social y económico que desempeñó la oligarquía ciudadana en general y de aquella de origen catalanoaragonés en particular, excluyendo el trabajo de Bruno Anatra sobre las clases dirigentes sasaresas ${ }^{85}$ y un proyecto conjunto basado en el estudio prosopográfico de las élites ciudadanas ${ }^{86}$. En ese sentido, la realidad tanto sasaresa como cagliaritana de finales del XV llama la atención sobre el rol que las oligarquías ciudadanas jugaron respecto a la corona y la administración regia y dejan entrever la necesidad de ulteriores profundizaciones que, afrontando las diversas realidades urbanas de la isla, ofrezcan una visión unitaria del encargo que afrontó la élite ciudadana en la historia del reino ${ }^{87}$.

De hecho, han sido pocos los aragoneses documentados en los protocolos cagliaritanos del siglo XV; pero ello no es óbvice para remarcar aquellos individuos más llamativos que pululan por la documentación investigada. A tal propósito responde el testamento de Antonio Durrea, nativo de Daroca, aunque en la data del documento (marzo 1498) estuviera domiciliado y casado en Cagliari ${ }^{88}$; o el caso de Juan Amador, mercader de Zaragoza, que participa en una venta de 16 quintales de queso de oveja por valor de 32 libras 16 sueldos (a razón de 41 sueldos el quintal) ${ }^{89}$; la estipulación de un censo donde aparece el personaje Juan Lupi del Frago, notario también zaragozano ${ }^{90}$; incluso el propio escribano Juan Carniçer originario de Maella, que firma como testigo en un acto de procuración ${ }^{91}$,

${ }^{84}$ D. IGUAL, Comercio y operadores económicos, citado, pp. 38-39.

${ }^{85} \mathrm{~B}$. ANATRA, I ceti dirigenti sassaresi nell'età aragonese e spagnola en Gli Statuti Sassaresi. Economia, società, istituzioni a Sassari nel Medioevo e nell'Età Moderna "Atti del Convegno di Studi» (Sassari, 1983), a cura di A. Mattone y M.Tangheroni, Cagliari, EDES, 1986, pp. 365 -

${ }^{86}$ M.E. Cadeddu; L. Gallinari; M.G. Mele; M.G. MElOni; A.M. Oliva; O. SvhenA, Elites y representaciones parlamentarias en la Cerdeña del siglo XV. Metodologías y perspectivas de investigación en "Actes del $53^{\circ}$ Congrés de la Comissió Internacional per a l'estudi de la Història de les Institucions Representatives i Parlamentàries", Barcelona, 2005, II, pp. 14311436.

${ }^{87}$ Un aspecto que resultaría interesante sería la investigación de los apellidos de familias de nobles aragoneses aparecidas en libros de autores italianos (Francesco FLORIS y Sergio SERRA, Storia della nobiltà in Sardegna. Genealogia e araldica delle famiglie nobili sarde, Cagliari, 1986 y. F. FLORIS, Feudi e Feudatari in Sardegna, Cagliari, 1996, 2 vols.) y su cotejo con la historigrafía ibérica (Por ejemplo con los linajes nobiliarios aragoneses en İsabel FALCON PÉREZ, Prosopografía de los infanzones de Aragón (1200-1410), Zaragoza, Universidad, 2003), pues parece ser que, en algunos casos, se detectan notables errores de transcripción.

${ }^{88}$ ASC, ANS, Carnicer, ff. $4 \mathrm{v}-5 \mathrm{v}$.

${ }^{89}$ Barbens V, 1474-VII-27, ff. $19 \mathrm{v}-20 \mathrm{v}$.

${ }^{90}$ Barbens XII, 1482-X-16, ff. 66 r-v.

${ }^{91}$ Barbens X, 1477-VII-22, f. $8 \mathrm{v}$. 
entre otros actores también significativos que quedan recogidos en la nómina del apéndice incluido al final.

También en Cataluña se aprecia un relativo crecimiento del interés por Cagliari en esta centuria, desde donde se constata un importante comercio de tejidos, cereal y coral sardo. Y es que Cerdeña funciona para el comercio catalán como escala de las rutas hacia Nápoles, Sicilia, Túnez o el Levante ${ }^{92}$. Algunos autores han apuntado a partir de la documentación barcelonesa de fines del Cuatrocientos, el relevante peso de las noticias referidas al comercio con la isla ${ }^{93}$, a pesar de la notoria y sobrevalorada preferencia por la ciudad de Alguero $^{94}$.

La gran movilidad territorial de los comerciantes y factores que aparecen actuando tanto en Cagliari como en la Península, dificulta esta tarea de identificación. De otra parte, el gran problema de las referencias notariales es la atribución de nacionalidad o procedencia; de hecho, algunos de ellos llegarán incluso a compartir dos o más ciudadanías a la vez en función de su propia conveniencia. Además, en ocasiones sólo su apellido delata un origen sardo o hispano de la familia. Pero lo cierto es que, con cuidado y paciencia, una investigación futura de esta índole permitiría trazar genealogías y perfilar las carreras profesionales de muchos individuos que actualmente aparecen desdibujados tras apellidos bastante comunes y muy abundantes. A veces, varios de ellos enmascaran una realidad familiar enormemente compleja y fluida, por lo que deben ser entendidos con la salvedad de que algunos de estos linajes no pueden ser comparados ni en importancia ni en representatividad, porque mientras unos constituyen verdaderas castas de anclada tradición en el panorama sardo (aunque posean apellidos de indudable estirpe catalanoaragonesa), otros en cambio es incluso discutible que sean de ascendencia propiamente ibérica.

\section{EL REFLEJO DE LAS RELACIONES \\ ENTRE CAGLIARI, VALENCIA Y ARAGÓN EN LA VIDA COTIDIANA}

En Cagliari, como en las tierras de la Corona, los notarios públicos desarrollan una actividad profesional próxima a la de redactores y conservadores de las relaciones y sentimientos individuales, siendo la persona encargada de conferir validez a los arreglos firmados en la esfera de la privacidad. Por eso los fondos notariales constituyen, a nuestro entender, un espejo fiel del devenir diario coetáneo, al ser fuentes primarias solventes para interpretar la

\footnotetext{
${ }^{92}$ Recomendamos leer a C. ZEDDA, Cagliari: un porto commerciale, citado, pp. 92-140.

${ }^{93}$ Roberto PILI, Considerazioni sul commercio nel Mediterraneo occidentale, seconda metà del XV secolo, "Estudis Historics i Documents dels Arxius de Protocols", XIV (1996), pp. 187204.

${ }^{94}$ En la preferencia catalana por Alghero ha insistido Francesco MANCONI, L'Alguer, un " puerto catalan en la ruta de Oriente en "Actas XVII Congreso Historia de la Corona de Aragón" (Barcelona-Lleida 2000), Barcelona, 2003, I, pp. 435-440.
} 
actividad humana, ya que sus actos acopian testimonios vertidos por protagonistas - conocidos o anónimos - que esbozan la cotidianeidad de las relaciones familiares, vecinales o laborales, con sus solidaridades y sus conflictos, sus momentos festivos y sus horas más confusas y amargas, fijando por escrito toda serie de acuerdos o pactos tan relevantes para ellos que querían otorgarles autenticidad y dejarlos recogidos y reconocidos de una manera oficial.

El recurso a la historia de género está especialmente bien tratado en la documentación cotejada. La sociedad femenina cagliaritana cuatrocentista disfruta de una cierta consideración como se desprende del gran número de actos donde van a actuar como protagonistas, ya sea al ser nombradas procuradoras de los propios maridos, tutoras de sus hijos o responsables del buen funcionamiento de los negocios de la familia. Un ejemplo del primer caso es el de Isabel Aragall, que en calidad de procuradora de su marido Giacomo Aragall, caballero cagliaritano, vende al mercader valenciano Raimundo Pardo una embarcación, concretamente una galeota bien equipada - primo cum arbore et pauca exarcia, cum antenis, cum duobus ruxons nous, cum pavesiis sive pavesos et tauleginis decem septem, cum remis triginta octo, cum duabus bombardiis et quinque mastilis, cum quinque lanceis magnis, cum undecim barrils bonis, cum exarcia et talles septem aut octo, cum vela nona, cum tribus spingardiis, cum timone, cum omni embarcamento, cum tenda et tendal et cum banqueris como resulta del inventario en posesión de Pardoy con todo a punto, la cual se encuentra amarrada en la dársena de Cagliari. El importe de 180 liras viene convenido en dos pagos: 80 el mismo día en que se estipula la venta y las 100 restantes serían pagadas por Pardo en un plazo de 10 días desde su regreso de un viaje que estaba a punto de cumplir y que debía ser finalizado con la recuperación de la suma mercante. La modalidad del pago es certificada en dos actos inmediatamente sucesivos: el albarán en el que Isabel declara haber recibido 80 alfonsinos y el empeño por parte de Raimundo de pagar el resto una vez regresara a Cagliari ${ }^{95}$.

Asiduamente se dan matrimonios entre nobles catalano-aragoneses con burgueses sardos, como el que tuvo lugar, a mediados del XV, entre Violante Sanjust, hija de Dalmau, señor de Villagreca y Furtei, y Giuliano Scamado, un rico mercader ${ }^{96}$. A pesar de que debe ampliarse la base empírica que facilite el análisis histórico de esta estrategia social, las referencias documentales halladas parecen indicar en este sentido. La constitución de dotes fue igualmente otra práctica muy extendida durante los siglos finales de la Edad Media ${ }^{97}$. Contamos con varios ejemplos, como el de Antonia, viuda del peletero Rafael Pontich, que contrae nuevas nupcias con Bartolomé Gamban, oficial aduanero de Valencia. Según una costumbre cagliaritana le aporta en

\footnotetext{
${ }^{95}$ ASC, ANS, Barbens I, 1469-VI-22, ff. $35 \mathrm{v}-37$ r.

${ }^{96} \mathrm{G}$. Olla REPETTO, La donna cagliaritana, citado, p. 174.

${ }^{97}$ Teresa VINYOLES VIDAL; Mireia "COMAS VIA, Relacions de gènere en el marc de l'expansió catalano-aragonesa a Sardenya en "Actas del XVIII Congreso de Historia de la Corona de Aragón", Valencia, 2005, vol. II, pp. 1755-1765.
} 
dote 120 liras de moneda alfonsina menuda repartidas de la siguiente manera: 20 liras en muebles y 100 liras en dinero efectivo, que le será dado por los herederos de su marido. De otra parte, Bartolomé, acogiéndola como su esposa, declara haber recibido la dote y de restiturila a ella o a quién por ella se digne, si se presentara la necesidad de hacerlo ${ }^{98}$. La dote era una de las maneras de conocer las formas jurídicas del matrimonio, como pasa en el acto de procura que el propio Pietro Steve concede a Giacomo Guill, hermano de su difunto padrastro, Fernando Guill, de Alicante, donde se distingue entre la donación por la virginidad y el screix (acrecentamiento) o donatio propter nubcias. En el documento se dice que Giacomo Franch, padre de Caterina, le dará una dote de 15.000 sueldos, de los cuales 2.000 serían invertidos en ropas de buena calidad a estima de dos buenas personas elegidas por ambas partes. En este caso, Pietro Steve dona a la mujer 7.000 sueldos por la virginidad, frente al screix de 22.000 y la hace entrar en posesión de la mitad dels draps de cambra de lli, de lana, de seda (e) de cotó ${ }^{99}$.

Como se puede apreciar, las licencias matrimoniales contraídas entre las mujeres sardas y los extranjeros, o viceversa, eran pocas. Por contraposición, están mejor documentados los matrimonios de viudas que pasan a contraer segundas nupcias. Es fácil notar que en la concesión de estas licencias, los vicarios no siempre especifican el oficio del esposo, más bien lo que recogen casi siempre es si éste habitaba en alguno de los apéndices cagliaritanos (Lapola, Villanova, Stampace) ${ }^{100}$. Se tiene noticia, por ejemplo, de que el vicario general del arzobispado envió al curado de la iglesia de Lapola la licencia de matrimonio para el mercader aragonés Martín Sanxis y la doncella Antonia, hija de Pietro Babaloni, herrero habitante en el apéndice ${ }^{101}$.

La condición de lucha cotidiana típica de aquellos que no contaron con grandes medios es bien recogida en varios documentos, como aquellos que conciernen a otras dos mujeres: Úrsula, que como vimos, se afana en liberar a su hija y en recobrar los bienes dejados; y Eleonora, también ella como viuda del colchonero Jacobo Ventura, junto a Juan Esplugues, mercader de Valencia, nombra procurador a su padre Bonanato Bonet, siendo propensa a la recuperación de la propiedad dejada en Valencia, cuyos bienes habían confiado en comanda a Luis Ferraio, mercader hijo de Juan Ferraio, también mercader de Valencia ${ }^{102}$.

\footnotetext{
${ }^{98}$ Barbens IV, 1474-III-6, ff. $12 \mathrm{v}-13 \mathrm{r}$.

${ }^{99}$ Steve, 1458-VII-28, ff. 48 r - 50 v.

${ }^{100} \mathrm{La}$ distribución y estructura urbana de la ciudad ha sido últimamente investigada por M.B. Urban, Cagliari aragonese. Topografia e insediamento, Cagliari, Consiglio Nazionale delle Ricerche, 2000.

${ }^{101}$ Barbens XIV, 1480-XII-5, f. 16 v.

${ }^{102}$ Barbens I, 1469-XI-6, ff. 43 r - 44 r.
} 
Aprovechando que ya hemos hablado en algún momento de los testamentos ${ }^{103}$, no se puede pasar desapercibido aquel en el que Jacobo Campos, habitante en Lapola, saldaba sus deudas y disponía ser sepultado en la iglesia de San Francisco de Stampace, dejando a su hermana Damiana Campos los bienes que tenía en el reino de Valencia y que consistían en tres cossin de tierra y un cofre, como sabía el mercader Pietro Carmere ${ }^{104}$. O ese otro donde Nicolás Gras, mercader residente en el Castillo de Cagliari, nombraba como ejecutor testamentario a su hermano Antonio Gras, mercader de Valencia, dejándole su parte del "navili" que poseían ${ }^{105}$.

Para completar el cuadro social cagliaritano es necesario hacer un breve apunte a la comunidad hebrea, cuya presencia en la parte del Castillo de Caller estuvo estrictamente ligada a la llegada de los aragoneses ${ }^{106}$. Los primeros años después de la conquista, la colonia judía o aljama se encontraba en una pequeña área del castillo, pero sucesivamente se fue alargando hasta extenderse en dos 'juharie' distintas. Ambas llegaron a ocupar, hacia la mitad del Cuatrocientos o bien en el momento de máxima expansión de la aljama, casi un tercio del mismo. La colonia estaba prevalentemente construida por mercaderes y comerciantes, pero también en menor medida por artesanos y médicos, éstos últimos muy apreciados por el mismo soberano aragonés ${ }^{107}$. Entre los comerciantes estaba bastante difundida la figura del corredor de oreja, un mediador de asuntos que se ocupaba de vender bienes por cuenta de terceros, manteniendo para sí una porcentual sobre la venta. En los actos del primer protocolo examinado de Barbens comparecen algunos nombres, como el de Salama Çaporta, nombrado deudor respecto a Pietro Roiç de Moros de la suma de 12 libras de moneda real valenciana.

Asimismo, los actos notariales cagliaritanos refieren numerosas noticias relativas a la compraventa de esclavos y a sus manumisiones ${ }^{108}$.

\footnotetext{
${ }^{103}$ Maria Giseppina MELONI, Pratiche devozionali e pietà popolare nei testamenti cagliaritani del Quattrocento en "Actas del XVII Congreso de Historia de la Corona de Aragón" (BarcelonaLleida 2000), Barcelona, 2003, vol. II, pp. 229-249.

${ }^{104}$ Garau III, 1452-X-23, f. 17 v - 18 r.

${ }^{105}$ Barbens VI, 1479-I-1, ff. 4 r - 5 r.

${ }^{106}$ Sobre la comunidad judía: Mauro PERANI, Appunti per la storia degli Ebrei in Sardegna durante la dominazione aragonese, "Italia", 5:1/2 (1985), pp. 104-144; C. TASCA, Gli ebrei in Sardegna nel XIV secolo. Società, cultura, istituzioni, Cagliari, 1992; G. OLLA REPETTO, Ebrei Sardi e Aragonesi nella Sardenga tardo medioevale, "Quaderni dell' Istituto di Studi Africani e Orientali. Orientalia Kalaritana", 3 (aprile 1998), pp. 233-246, de la misma Contributi alla storia degli Ebrei nel Regno di Sardegna e Corsica, "Medioevo. Saggi e Rassegne", 23 (1998), pp. 155178 y Organizzazione della società ebraica cagliaritana nel 300 en "Actas del XVII Congreso de Historia de la Corona de Aragón", Barcelona, 2003, vol. II, pp. 295-313; y, por último, M.E. CADEDDU, Elites urbane, ebrel e leggi suntuarie a Cagliari in età medioevale en R. FERRERO MICÓ (coord.), Autonomía municipal en el mundo mediterráneo: historia y perspectivas (Congreso celebrado en Valencia y Alpuente, 16-18 noviembre 2000), Valencia, 2002, pp. 229244.

${ }^{107} \mathrm{El}$ sector de la medicina se encuentra ampliamente representado en la familia Torrella, cuya historia se desarrolla entre Valencia, Cagliari, Nápoles y Roma. Para tal avatar consultar A.M ${ }^{a}$. OLIVA; O. SCHENA, I Torrella, una famiglia di medici tra Valenza. Sardegna e Roma en Alessandro VI. Dal Mediterraneo all'Atlantico "Atti del Convegno" (Cagliari 2001), Roma, 2004, pp. 115-146.

${ }^{108}$ Para obtener una información más completa consultar Carlo PILLAI, Schiavi orientali a Cagliari nel Quattrocento, "Medioevo. Saggi e Rassegne", 10 (1985), pp. 65-88.
} 
Pongamos por caso el de Bernat Montalla, mercader de Cagliari, que vende a Antoni Raymundo, correero ciudadano de Valencia, un esclavo sarraceno llamado Alí de Ora, de entre 23 y 25 años de edad, al precio de 90 liras alfonsinas. Finalmente fue acordado por ambas partes, que Bernat Montalla había tenido por su cuenta el esclavo durante el tiempo en que Antoni Raymundo había estado ausente, contemplando también los posibles casos de fuga o muerte del esclavo, mientras que dos personas elegidas por las partes habían tenido en cuenta la del trabajo y la renta del esclavo ${ }^{109}$. O el ejemplo de Giovanni Planes, mercader habitante en Cagliari, que confiesa deber 70 libras a Gaspar Villarreal, mercader de Valencia, por un siervo negro no esclavo $^{110}$. Tres meses más tarde Villarreal declara ante el notario Pietro Gomiç y ante el mercader Michele Rodes, ejecutores testamentarios de Giovanni Planes, de haber recibido las 70 libras en diversas soluciones como saldo de una deuda contraída por el mismo Planes ${ }^{111}$.

Particularmente curioso parece un documento redactado en Nápoles por el notario Steve el 24 de abril de 1458. Se trata de un acto de reconocimiento o, si se quiere, una declaración de paternidad. En él se observa como Fernando Diebra, rector y párroco de Ulldemolins en la diócesis de Tarragona, pide a una tal Elena siracusana que le confirme si la criatura de 13 meses que tiene en sus brazos, de nombre Policena, es hija de ella o suya. La declaración y petición por parte de Diebra se hace con el fin de que pueda legar una parte de sus bienes a la hija. Del acto se deduce que el hecho de que un sacerdote tuviera hijos no debía ser algo extraordinario, ya que si el Diebra no se avergüenza de tratar el caso e incluso de confiarlo sobre un acto publico, nos hace pensar que seguramente no se temerían sanciones eclesiásticas. Deducimos igualmente que el sacerdote vino a Nápoles donde tuvo que conocer a dicha mujer, la cual evidentemente no llevaría una vida muy regular, cuando el mismo Diebra la obligó a prestar juramento sobre los evangelios ante el notario y los testigos de que la niña fuera hija suya ${ }^{112}$.

También el compromiso que unía a un aprendiz o un mozo con un maestro o profesional de un oficio, para que a cambio de ayuda y obediencia la transmitiera los conocimientos de su arte y pudiera luego ganarse la vida, asoma entre un sinfín más de actos relativos a las manifestaciones vitales de una sociedad que creía en los textos escritos y que acudía al notario varias veces a lo largo de su vida. Así, el 19 de junio de 1393, Salvador ça Real, hijo de un ciudadano de Morella, se contrató a la edad de 17 años con Jaume Exarch, mercader de Cagliari causa adiscendi dictam vestram mercaturie durante dos años ${ }^{113}$.

\footnotetext{
${ }^{109}$ Garau I, 1443-II-20, ff. 57 r-v.

${ }^{110}$ Leytago, 1487-II-3, f. 83 r.

${ }^{111}$ Ibidem, 1487-V-11, ff. 88 r-v.

${ }^{112}$ Steve, ff. $44 \mathrm{r}-\mathrm{v}$.

${ }^{113}$ Cfr. E. CRUSELLES, Los comerciantes valencianos del siglo XV y sus libros de cuentas, Castellón, 2007, p. 88.
} 
En síntesis, entre tantos, algunos detalles de los protocolos permiten individualizar en qué campos era más vivaz y activa la circulación de las ideas, debido al afluir de intelectuales, artistas y artesanos ibéricos en la isla, sobre la estela de la actividad económico-social. De ahí que si nos detenemos en revisar las más variopintas situaciones a las que da lugar la observación de este plano, se pueda constatar el incipiente tránsito de la vieja mentalidad medieval a la introducción paulatina de la nueva cultura humanística en los albores de los tiempos modernos.

\section{OTROS MODELOS DE INVESTIGACIÓN DESARROLLADOS EN LAS ISLAS DEL MEDITERRÁNEO}

Nuestra labor de investigación se ha visto compaginada y complementada con los objetivos que ya fueron planteados en mi proyecto de tesis doctoral, que versó sobre el tema de la movilidad social y las relaciones económicas entre los reinos de Aragón y Valencia en el siglo $\mathrm{XV}^{114}$, ya que a ello ha contribuido la búsqueda de modelos similares de investigación en clave de perspectiva de historia comparada.

De este modo, a nivel insular algunos autores han puesto de relieve la importancia que tiene el estudio de dos zonas territoriales conectadas entre sí por las distintas relaciones en el plano socio-económico-comercial, pero también en el ámbito político, cultural y artístico. Son los casos de los trabajos de Onofre Vaquer Bennasar ${ }^{115}$ para las Baleares (el reino de Mallorca se conquistó en 1229 por iniciativa de Jaime I, nieto de Alfonso II, integrando como islas adyacentes a Ibiza y Menorca), que evidencian el fenómeno de la inmigración de extranjeros a la ciudad de Mallorca durante los siglos XV y XVI; y de Giuseppe Petralia ${ }^{116}$ que afronta principalmente el problema de la emigración bajomedieval pisana en Sicilia, abordándolo desde la perspectiva del método y los perfiles prosopográficos, que tanto nos interesa. Además del estudio sobre extranjeros en Sicilia y Cerdeña en los siglos XIII-XV, bajo

${ }^{114}$ C. VILlANUEVA MORTE, Movilidad social y relaciones económicas entre los reinos de Aragón y Valencia en el siglo X $V$, Tesis doctoral publicada en CD-ROM, 4 vols, dirigida por Germán Navarro Espinach, profesor titular del Dpto. Historia Medieval en la Facultad de Filosofía y Letras de Zaragoza, defendida en la modalidad de Doctorado Europeo.

${ }^{115}$ Onofre VAQUER BENNASAR, Inmigrants a Mallorca a la segona meitat del segle XV, "Bolletí de la Societat Arqueologica Lul.liana", 51 (1995), pp. 125-140 y 55 (1999), pp. 353 3-362 Inmigrants a la ciutat de Mallorca, 1448-1598 en "Actas del XVII Congreso de Historia de la Corona de Aragón" (Barcelona-Lleida, 2000) Barcelona, 2003, pp. 445-455; y El comerç marítim de Mallorca, 1448-1531, Palma de Mallorca, 2001.

${ }^{116}$ Giuseppe PETRALIA, Ricerche prosopografiche sull'emigrazione delle famiglie mercantili pisane in Sicilia dopo la conquista fiorentina del 1406 "Bolletino Storico Pisano", 50 (1981) pp. 37-93; segunda parte en el mismo boletín $n^{\circ} 51$ (1982), pp. 229-270; tercera parte en n ${ }^{0} 52$ (1983), pp. 91-115 y la cuarta en no 53 (1984), pp. 147-185. Frente a su libro sobre Banchieri e famighie mercantili nel Mediterraneo aragonese. L'emigrazione dei pisani in Sicilia nel Quattrocento, Pisa, Pacini, 1989 y sus ya numerosos artículos sobre el mismo tema: Mercanti e famiglie pisane in Sicilia nel XV secolo, "Annuario del'Istituto Storico Italiano per l'età moderna e contemporanea", 33-34 (1981-82), y Per la storia dell'immigrazione quattrocentesca da Pisa e della migrazione Toscana-Sicilia nel Basso Medioevo en Strutture familiari, epidemie, migrazioni nell'Italia medievale, a cura di R.Comba-G. Piccini-G. Pinto, Napolés, 1984. 
cargo de Marco Tangheroni ${ }^{117}$, donde para la segunda destaca el artículo realizado por Sandro Petrucci ${ }^{118}$; y más recientemente el de Ricardo Franch Benavent ${ }^{119}$, tratando el tema de la corriente migratoria protagonizada por los italianos que se asentaron temporal o definitivamente en España durante la época moderna, y más concretamente analizando el origen y actividad laboral que desempeñaron los inmigrantes italianos avecindados en Valencia en el siglo XVI.

Es cierto que el tema de las relaciones entre Cataluña y las diversas islas del Mediterráneo central y levantino ha sido plasmado en distintos trabajos de diversa naturaleza, fundamentalmente liderados por Francesco Manconi $^{120}$, Ennio Igor Mineo ${ }^{121}$, Carlo Livi ${ }^{122}$, Carmen Batllé ${ }^{123}$, Joan F. Cabestany ${ }^{124}$, Sergio Serra ${ }^{125}$, María Teresa Ferrer ${ }^{126}$ y tantos otros. En cambio, las relaciones con el resto de estados de la Corona, salvo rara excepción $^{127}$, aún está en volandas.

De igual manera, la relación entre Mallorca y Cerdeña ha sido objeto de numerosas páginas dedicadas a su estudio, entre las que destacan los

${ }^{117}$ Commercio, finanza, funzione publica. Stranieri in Sicilia e in Sardegna nei secoli XIII-XV, a cura di M. TANGHERONI, Napoli, GISEM Liguori, 1989.

${ }^{118}$ Sandro PETRUCCI, Forestieri a Castello di Castro in periodo pisano en Commercio, finanza, citado, pp. 219-259.

${ }^{119}$ Ricardo FRANCH BENAVENT, La inmigración italiana en la España moderna en “Actas del Coloquio sobre La inmigración en España , Santiago de Compostela, 2004, pp. 103-145.

${ }^{120} \mathrm{~F}$. MANCONI, Les relacions econòmiques i socials de Catalunya amb Sardenya entre l'Edat Mitjana i l'Edat Moderna, "Revista de l'Alguer. Periódic de Cultura dels Paisos Catalans" 1 (diciembre 1990), pp. 73-95; El llegat cultural català a Sardenya "Serra d'Or", 451-452 (1997), pp. 26-29; Catalogna e Sardegna: relazioni economiche e influssi culturali fra Quattro e Cinquecento en La Sardegna e la presenza catalana nel Mediterraneo "Atti del VI Congresso dell Associazione Italiana di Studi Catalani” (Cagliari 1995), a cura di P. Maninchedda, vol. I, Cagliari, 1998, pp. 35-54; De no poderse desmembrar de la Corona de Aragón: Sardenya Paisos Catalans, un vincle de quatre segles, "Pedralbes. Revista d'història moderna", 18 (1998) pp. 179-194; El reino de Cerdeña de Fernando II a Carlos V: el largo camino hacia la modernidad en E. Belenguer Cebrià (coord.), De la unión de la Corona al Imperio de Carlos $V$, Madrid, 2001, vol. II, pp. 15-53; y L'identità catalana della Sardegna, "Isole nella storia. Cooperazione Mediterranea", I-2 (2003), Anno XV, pp. 105-112.

${ }^{121}$ Ennio Igor MINEO, Egemonia e radicamento della nobiltà militare catalana in Sicilia dopo il 1392: l'esempio dei Cruilles e dei Santapau en Commercio, finanza, citado, pp. 89-127.

${ }^{122}$ Carlo LIVI, I rapporti fra Sardi e Catalani nel tardo medioevo: il caso dell'Ogliastra en La Corona d'Aragona in Italia (secc. XIII-XVIII) "Atti del XIV Congresso di Storia della Corona d'Aragona", Sassari, 1995, vol. 2: 2, pp. 493-527.

${ }^{123}$ Carmen BATLle GALLART, Noticias sobre los negocios de mercaderes de Barcelona en Cerdeña hacia 1300 en La Sardegna nel mondo mediterraneo "I Convegno Internazionale di Studi geografico-storici", Sassari, 1981, pp. 277-289.

${ }^{124}$ Joan F. CABESTANY FORT, I mercanti catalani e la Sardegna en I catalani in Sardegna, 1984, pp. 25-34.

${ }^{125}$ Sergio SERRA, Les grans famílies sardo-catalanes en Els catalans a Sardenya a cargo de J. Carbonell y F. Manconi, Barcelona, 1984, pp. 211-216; y L'Araldica catalana in Sardegna en "Atti XIV Congresso di Storia della Corona d Äragona”, Sassari, 1997, vol. 5, pp. 583-595.

${ }^{126}$ María Teresa FERRER I MALlol, Els catalans a la Sardenya medieval, "Serra d'Or", 451452 (1997), pp. 22-25.

${ }^{127} \mathrm{El}$ tema de las características de la migración ibérica en la isla sarda fue abordado en la conferencia inédita de $\mathrm{M}^{\mathrm{a}}$.E. CADEDDU, Migraciones ibéricas en Cerdeña (ss. XIII-XV). Historia de conflictos e integración en "I Curso de especialización de Historia Medieval: La gẹ́nesis de la vida civil. Sociología política y gestión económica en las ciudades medievales", organizado por el Dpto. de Historia Medieval de Valencia y celebrado en Simat de la Valldigna (13-16 julio 2006). 
trabajos de María Barceló ${ }^{128}$, Pau Cateura ${ }^{129}$ y David Abulafia ${ }^{130}$. Pero de todo ello es el caso de Onofre Vaquer el que nos llama especialmente la atención, ya que -como aquí pretendemos- ha documentado un buen número de aragoneses y valencianos exhumados de los protocolos notariales mallorquines.

La totalidad de los inmigrantes de los que este autor ha podido conocer su procedencia asciende para la segunda mitad del siglo XV a 132 valencianos $(19,07 \%)$ y 34 aragoneses $(4,91 \%)$. La característica esencial es que casi todos estos personajes se quedan a vivir en la ciudad, muy pocos los que se van a los pueblos. Sin embargo, no todos los inmigrantes documentados se quedan a vivir para siempre en Mallorca, puesto que muchos de ellos practican una inmigración temporal, especialmente los marineros, patronos y mercaderes, aunque también podemos señalar que muchos de ellos contraen aquí matrimonio.

La documentación no siempre indica la profesión o condición de los inmigrantes, pero hay que suponer que el gran grueso estaría representado por los mercaderes venidos de fuera que se establecen en Mallorca para comerciar o vienen solamente para hacerlo. Vaquer computa para la segunda mitad del siglo XV un total de 149 mercaderes procedentes de Valencia (de los cuales 43 son residentes en la isla) y 17 de Aragón (de ellos 8 son residentes). Mientras que para Cerdeña la cifra alcanza los 41 (16 residentes), estando por debajo Sicilia con 23 (10 residentes). Como podemos observar los valencianos es el segundo grupo más numeroso tan solo superados por los catalanes con 265 representantes (84), siendo los más poderosos las familias conversas de los Santángel, Bellviure, Vives, establecidos durante años en la isla. Los aragoneses documentados son menos numerosos, si bien cabe destacar de entre ellos una importante familia también de conversos establecida, ya para siempre, en la isla, los Caballería. Estas cifras contrastan con las tomadas para la primera mitad del XVI, ya que vemos como el número de valencianos disminuye notablemente ( 31 , de los cuales 25 son residentes), mientras que el de aragoneses se mantiene con ligero descenso (10, de ellos 7 residentes). Al igual que ocurre con Cerdeña (de 12, 11 son residentes) y Sicilia (11 todos ellos con residencia en Mallorca).

De Valencia vienen menestrales relacionados con la manufactura de la seda: velluters (un total de 10 documentados, frente a otro de Aragón), torcedores y tintoreros de seda. En la segunda mitad del XV encontramos asimismo: 5 gerrers valencianos, de los que cuatro son de Paterna; de las

\footnotetext{
${ }^{128}$ María BARCELÓ CRESPÍ, Relaciones comerciales entre Mallorca y Cerdeña: segunda mitad del siglo XV en "Actas del XIV Congreso de Historia de la Corona de Aragón", Sassari, 1996, vol. 3, pp. 101-121.

${ }^{129} \mathrm{Pau}$ CATEURA BENNASSER, El comercio del reino de Mallorca con „Cerdeña a través de los 'guiatges'en "Atti del XIV Congresso di Storia della Corona d'Aragona", Sassari, 1995, vol. II: 1 , pp. 277-290.

${ }^{130}$ David ABULAFIA, Le relazioni fra il regno di Maiorca e la Sardegna, 1267-1324 en La Corona d'Aragona in Italia (secc. XIII-XVIII) "Atti del XIV Congresso di Storia della Corona d'Aragona", Sassari, 1995, vol. 2:1, pp. 11-31.
} 
prostitutas 8 son de la capital del Levante, 5 de Castilla, 1 de Nápoles, 1 de Navarra, 1 de Aragón y 1 de Florencia, 3 concubinas son del País Vasco y una de Andalucía. Los argenteros vienen sobre todo de Cataluña, pero también de Valencia, Aragón y Nápoles. Un jabonero es de Zaragoza y otro de Lérida. Por otro lado, los sastres son los menestrales más numerosos de los inmigrantes, de entre todos ellos 5 proceden de Valencia.

En la ciudad además de los inmigrantes de fuera de la isla, habían personas de la parte foránea asentados en topografías extrañas. Algunos iban a realizar el aprendizaje de un oficio de la mano de un maestro que los instruyera tanto personal como laboralmente. Pero ¿cómo se inmigraba? La mayoría de los inmigrantes son jóvenes varones que dejan a sus padres en sus lugares de origen para buscar faena. Muy común era enrolarse como marineros y al frecuentar el puerto de la isla se quedaban a vivir en la ciudad casándose con una mallorquina. Muchos de los linajes de estos inmigrantes no arraigaron en Mallorca. La mayoría que sí lo hicieron fueron los catalanes, aunque hay que tener presente que algunos de estos apellidos considerados catalanes pueden tener otro origen. Veamos los dos ejemplos que nos interesan: de Aragón son los linajes de Aragó, Barceló, Bertran, Bonet, Cerdà, Cortés, Cruelles, Dalmau, Esteva, Isern, March, Marí, Ramon, Vidal, Xemenis (de donde derivarían Ximelis y Xamena); frente a los del reino de Valencia más numerosos, como son los Alzina, Arbona, Arnau, Ballester, Bernat, Bertran, Bonet, Borrás, Cardona, Castelló, Domènech, Escales, Esteva, Falcó, Ferrando, Fortesa, Garau, García, Genovard, Gil, Gomila, Joan, Lladó, Llopis, Marqués, Martí, Mas, Massot, Mateu, Mayans, Mercadal, Mercader, Mir, Mora, Morell, Nadal, Oliver, Oriola, Pasqual, Pomar, Puig, Quintana, Ramon, Sagrera, Sala, Salort, Segura, Servera, Soler, Solivella, Thomás, Torrent, Torres, Valls, Vanrell, Vich y Vidal ${ }^{131}$; algunos de los cuales nos encontramos operando también en la ciudad de Cagliari.

Finalmente, hay que reseñar que el listado de inmigrantes valencianos $y$ aragoneses que este historiador ha documentado en Mallorca se caracteriza porque además de mercaderes que, por otra parte, constituyen la gran mayoría, prevalecen profesiones relacionadas con el mar y algunas mujeres, de las que la mayoría son prostitutas. En unos casos constan como residentes en la isla, aunque no todos ellos se tenga la certeza de que estuvieran domiciliados.

\footnotetext{
${ }^{131}$ Cfr. O. VAQUeR, Immigrants a la ciutat de Mallorca. 1448-1598, citado, pp. 451-452.
} 


\section{CONCLUSIÓN}

A modo de colofón, se puede decir que aparte de las interacciones mercantiles que aquí se han detallado con la continua ida y venida de uno a otro lugar de naves, productos, mercaderes y patrones, y por ejercer la isla de Cerdeña, para el comercio exterior valenciano una función de escala técnica y comercial para otros puertos mediterráneos, esta ruta de la diagonal insular comprendía otros aspectos como las transferencias culturales, sociales y familiares que convergen también en buena medida en las relaciones entre estos dos espacios económicos. El afrontar un deseable paradigma de historia comparada entre las fuentes archivísticas sardas con las ibéricas nos está permitiendo gradualmente hacer notar la diferencia de criterios o de puntos de vista y conocer mejor el sentido que tuvieron para Cerdeña los contactos recíprocos establecidos con Valencia y Aragón y a la inversa, durante mediados del siglo XV al menos hasta los albores del XVI. Al tiempo que sirve para corroborar que los protocolos de Cagliari sirven para conocer las actividades económicas tanto de sus propios hombres de negocios y de todos aquellos que procedentes de lugares muy diversos desarrollan acciones en la isla. De ellos, se puede deducir la capacidad económica de los negociantes valencianos y aragoneses que intervienen en el comercio exterior, y es fácil poner en relación las actividades desplegadas con los circuitos más activos de ámbito europeo, tanto mediterráneos como continentales.

Como hemos podido comprobar, nos enfrentamos al vaciado operativo de un material documental, milagrosamente conservado, aunque no siempre en buenas condiciones de lectura, difícil de trabajar por la lentitud exigida y por la dificultad de elevar su información por encima de la anécdota o del hecho aislado, y que constituye una parte importantísima de nuestro trabajo. La labor no está, ni mucho menos, concluida, pero la información rescatada consideramos que es lo suficientemente amplia y expresiva como para dar apoyatura a la tesis trazada de intentar desvelar la proporción de presencia valenciano-aragonesa, pues, creemos que hemos contribuido a captar la dimensión humana de esos protagonistas y a garantizar en cierta medida una cota de comprensión y evolución suficiente de los fenómenos analizados.

No obstante, somos conscientes de que no hemos agotado en absoluto las posibilidades que ofrecen esta multitud de instrumentos, el camino es largo y todavía queda por renovar los conocimientos actuales de la mano de sucesivos sondeos prosopográficos exhaustivos a través de los fondos documentales valencianos o aragoneses, entre ellos con la ya iniciada consulta de los fondos notariales depositados en el Real Colegio Seminario de Corpus Christi de Valencia (Archivo de Protocolos del Patriarca) y del Archivo Histórico de Protocolos de Zaragoza; y de otras áreas, en concreto de la sección dedicada a Cerdeña del Archivo de la Corona de Aragón de 
Barcelona $^{132}$, el Histórico Nacional de Madrid ${ }^{133}$, el General de Simancas ${ }^{134}$ y el del Reino de Mallorca ${ }^{135}$, en cualquier caso con vistas a reconstruir la evolución socioeconómica y demográfica de los tres observatorios referenciados. A modo de reto, abogamos por la creación de unas bases sentadas en el trabajo en equipo y en la máxima cooperación interdisciplinar.

Por la flexibilidad de contenidos e intenciones de estos documentos notariales, hemos encontrado una fuente de información muy importante para la labor investigadora de los historiadores, a los que desde estas líneas queremos recordarles la consabida riqueza de los protocolos cagliaritanos, tanto por sus características históricas, sociológicas, lingüísticas, paleográficas y diplomáticas, etc., que nos abren ventanas a muchas posibilidades de estudio e investigación. A los que habría que añadir la aconsejable labor de consulta de otra variada gama de fuentes archivísticas que todavía nos falta por explorar, preferentemente los pergaminos ${ }^{136}$ y las cartas reales ${ }^{137}$, con naturalezas institucionales diversas y grados de intencionalidad complementarios, que además de diversificar la fuente notarial y proporcionar un enriquecimiento al análisis de la misma, hace que sin duda nos enfrentemos a una de las herramientas pragmáticas más útiles, $y$, por ende, un punto de referencia indispensable para los interesados en este campo temático que aquí nos ha ocupado.

En la vida económica y comercial cagliaritana desempeñaron un importante papel los hombres de negocios y los mercaderes valencianos que, atraídos por las posibilidades que Cagliari ofrecía, tomaron morada en la ciudad. Hay en particular algunos personajes, que mantuvieron estrechas relaciones con Valencia y su territorio a mediados del Cuatrocientos; éstos fueron, entre otros, Pere Fortuny y los miembros de las familias Blasco y

\footnotetext{
${ }^{132} \mathrm{M}^{\mathrm{a}}$.G. MELONI, Una nota su alcuni documenti in lingua sarda dell'Archivio della Corona d'Aragona, "Medioevo. Saggi e Rassegne», 20 (1995), pp. 353-364. Frente a la documentación que podemos encontrar en otros archivos catalanes como Maria Mercè COSTA I PARETAS, Sardenya en els arxius catalans en Els catalans a Sardenya, Barcelona, 1984, pp. 193-197; y Jesús MASSIP FonOLlOSA, La documentació sarda de l'Arxiu Historic de Tortosa en "Actas del XIV Congresso di Storia della Corona d'Aragona”, Sassari, 1996, vol. 3, pp. 595-605.

${ }^{133}$ A este respecto se podría iniciar con Francina SoLSONA CLIMENT, Documentos referentes a Cerdeña en la sección de manuscritos de la Biblioteca Nacional de Madrid en "Actas VI Congreso Historia de la Corona de Aragón" (Cerdeña 1957), Madrid, 1959, pp. 493-521.

${ }^{134}$ José Luis RoDRÍGUEZ DE DIEGO, Fondos documentales sobre Cerdeña en el Archivo General de Simancas en Istituzioni rappresentativa nella Sardegna medioevale e moderna "Atti Seminario regionale de studi 1984", Cagliari, 1989, pp. 271-283.

${ }^{135}$ Antonio MUT CALAFELL, Fuentes documentales para la historia de Cerdeña en el Archivo del Reino de Mallorca en Istituzioni rappresentativa nella Sardegna, citado, pp. 215-225; y Ana Margarita CONDE RIERA y Laura Margarita MARCÚS MAIMÓ, Notas referentes a Cerdeña de la serie 'Lletres comunes' del Archivo del Reino de Mallorca (1336-1387) en "Atti XIV Congresso di Storia della Corona d'Aragona", Sassari, 1996, vol. 3, pp. 271-286.

${ }^{136}$ Para una orientación general sobre los fondos documentarios existentes en el Archivio Storico del Comune di Cagliari y para un primer examen en regesto de la documentación redactada en pergamino remitimos a la obra de S. LIPPI, L'Archivio Comunale di Cagliari. Sezione Antica, Cagliari, 1897, pp. 117-255.

${ }^{137}$ Archivio di Stato di Cagliari. Antico Archivio Regio, Pragmatiche, istruzioni e carte reali, Serie B1, estudiadas por Agustín F. del VALLE PANTOJO, Las cartas reales de la Cancillería de Aragón en el Archivo de Estado de Cagliari (1398-1501), "Acta Historica et Archaeologica Mediaevalia”, 25 (2003-2004), pp. 903-923.
} 
Bertrán, linajes de carácter judeoconverso muy destacado, en tal grado de profusión que resulta casi imposible esclarecer la embrollada red de negocios y familias que mantuvieron.

De todas formas, los vínculos y conexiones entre Cerdeña, Valencia y Aragón no se redujeron a la actividad de estos personajes apenas recordados, puesto que hubo todo un mundo de pequeños, medianos y grandes mercaderes, de marineros y aventureros que emerge de los protocolos notariales cagliaritanos. Un trasiego constante y rentable de personas desde los distintos reinos peninsulares o estados miembros que integraban la Corona de Aragón a la isla y, muchas veces en sentido contrario, que es necesario estudiar en toda su complejidad y desde la perspectiva de la larga duración.

Fecha de recepción del artículo: junio 2007.

Fecha de aceptación y versión final: enero 2008. 


\section{APÉNDICE}

\section{A) FUENTES ARCHIVÍSTICAS}

ARCHIVIO DI STATO DI CAGLIARI

Atti Notarili, Tappa d'insinuazione di Cagliari, Sez. II: Atti originali sciolti.

\begin{tabular}{|c|c|c|c|c|c|}
\hline NOTARIO & PERÍODO & VOLUMEN & N'PROT. & AÑOS & FOLIOS \\
\hline BASTER, Pietro & $1430-1433$ & 45 & 1 & $1430-33$ & $1-32 v$ \\
\hline \multirow{16}{*}{ BARBENS, Andrea } & \multirow{16}{*}{$1468-1484$} & \multirow{16}{*}{51} & 1 & $1468-69$ & $1-49 v$ \\
\hline & & & 2 & 1470 & $1-20 v$ \\
\hline & & & 3 & 1473 & $1-10 v$ \\
\hline & & & 4 & 1474 & $1-18 v$ \\
\hline & & & 5 & 1474 & $1-36 v$ \\
\hline & & & 6 & $1478-79$ & $1-30$ \\
\hline & & & 7 & 1480 & $1-9 v$ \\
\hline & & & 8 & 1481 & $1-14 v$ \\
\hline & & & 9 & 1483 & $1-20 v$ \\
\hline & & & 10 & 1477 & $1-41$ \\
\hline & & & 11 & 1479 & $1-77 v$ \\
\hline & & & $12 / 1$ & 1482 & $1-92$ \\
\hline & & & $12 / \|$ & 1482 & $1-16 v$ \\
\hline & & & 13 & $1469-70$ & $1-45 v$ \\
\hline & & & 14 & $1480-82$ & $1-147$ \\
\hline & & & 15 & $1483-84$ & $1-173 v$ \\
\hline CARNICER, Giovanni & $1498-1511$ & 118 & 1 & 1498-1511 & $1-24$ \\
\hline \multirow{4}{*}{ DE ARANDA, Stefano } & \multirow{4}{*}{$1448-1458$} & \multirow{4}{*}{254} & $\overline{11}$ & 1448 & $1-33$ \\
\hline & & & 2 & $1453-54$ & $1-106 v$ \\
\hline & & & 3 & 1455 & $1-65 v$ \\
\hline & & & 4 & 1458 & $1-34 v$ \\
\hline \multirow{3}{*}{ DURANTE, Pietro } & \multirow{3}{*}{$1459-1464$} & \multirow{3}{*}{268} & 1 & 1459 & $1-16 v$ \\
\hline & & & 2 & 1463 & $1-163 v$ \\
\hline & & & 3 & 1464 & $1-14 v$ \\
\hline \multirow{3}{*}{ GARAU, Giovanni } & \multirow{3}{*}{$1441-1460$} & \multirow{3}{*}{337} & 1 & $1441-43$ & $1-76 v$ \\
\hline & & & 2 & 1454 & $1-204 v$ \\
\hline & & & 3 & $1441-60$ & $1-30 v$ \\
\hline \multirow{2}{*}{ LEYTAGO, Michele } & \multirow{2}{*}{$1485-1487$} & \multirow{2}{*}{379} & 1 & Minuta & $1-60 v$ \\
\hline & & & 2 & Repertorio & $61-118$ \\
\hline STEVE, Pietro & $1456-1464$ & 1164 & 1 & $1456-64$ & $1-148 \mathrm{v}$ \\
\hline
\end{tabular}

ARCHIVO DE PROTOCOLOS DEL PATRIARCA (VALENCIA)

Fondos notariales del Real Colegio Seminario de Corpus Christi de Valencia

\begin{tabular}{|c|c|c|c|c|}
\hline NOTARIO & LOCALIDAD & AÑOS & LIBRO & SIGNATURA \\
\hline \multirow{5}{*}{$\begin{array}{l}\text { BARBENÇ, } \\
\text { Andreu }\end{array}$} & \multirow{5}{*}{ Valencia } & 1449 & Protocolo & 24630 \\
\hline & & 1456 & “ & 24631 \\
\hline & & 1457 & “ & 24634 \\
\hline & & 1462 & " & 24632 \\
\hline & & 1466 & “ & 24633 \\
\hline \multirow{4}{*}{ CARNICER, Joan } & \multirow{4}{*}{ Valencia } & 1469 & Protocolo & 27252 \\
\hline & & $1472-74$ & “ & 27253 \\
\hline & & 1475 & " & 27254 \\
\hline & & $1476-77$ & “ & 27255 \\
\hline
\end{tabular}




\section{B) AUTORES Y DESTINATARIOS VALENCIANOS Y ARAGONESES CENSADOS EN LOS PROTOCOLOS NOTARIALES CAGLIARITANOS (SIGLO XV)}

\begin{tabular}{|c|c|c|c|c|c|c|}
\hline NOMBRE & PROFESIÓN & $\begin{array}{l}\text { LOCALIDAD } \\
\text { ORIGEN }\end{array}$ & $\begin{array}{l}\text { RESIDEN- } \\
\text { TE } \\
\text { (Condición) }\end{array}$ & FECHA & $\begin{array}{l}\text { TIPO } \\
\text { DOC. }\end{array}$ & $\begin{array}{l}\text { REF DOCUMENTAL } \\
\text { (Notario, } \mathbf{n}^{0} \text { Prot., folio) }\end{array}$ \\
\hline [...]REOS, Juan & presbítero & Nules & - & 1455-VII-17 & procura & G. Garau, 2, 145r \\
\hline AGUSTÍN, Francisco & mercader & Valencia & - & $1480-\mathrm{XI}-13$ & Testigo & $\begin{array}{l}\text { A. Barbens, } 14,13 \mathrm{r} y \\
61 \mathrm{r}\end{array}$ \\
\hline Alcarás & - & Aragón & - & 1487-VII-24 & Venta & M. Leytago, $2,101 \mathrm{v}$ \\
\hline AMADOR, Juan & mercader & Zaragoza & $\begin{array}{llll}- & \\
\end{array}$ & $1474-$ VII-27 & Venta & A. Barbens, $5,19 \mathrm{v}-20 \mathrm{v}$ \\
\hline ANDRÉS, Gaspar & sastre & Valencia & - & 1469-IX-18 & Testigo & A. Barbens, 1, 40r \\
\hline ARAGONÉS, Jacobo & escudero & Valencia & - & 1469-VI-19 & Testigo & A. Barbens, 1, 32v \\
\hline ARNALDO, Juan & - & Valencia & - & 1455-VII-11 & Procura & G. Garau, 2, 139r \\
\hline ASBERT, Antonio & aludero & Valencia & - & $1470-\mathrm{V}-24$ & Testigo & A. Barbens, $2,8 \mathrm{r}$ \\
\hline AZNAR, Vicente & mercader & Valencia & - & $\begin{array}{c}1463-\mathrm{VI}-2 / \\
\mathrm{X}-31 / / \\
1470-\mathrm{VI}- \\
12 / 16\end{array}$ & $\begin{array}{l}\text { Testigo / } \\
\text { seguro / } \\
\text { procura }\end{array}$ & $\begin{array}{l}\text { P. Durante, } 2,63 \mathrm{r} y \\
129 \mathrm{r} \\
\text { A. Barbens, } 2,11 \mathrm{v}-13 \mathrm{r} \text {, } \\
14 \mathrm{v}-15 \mathrm{v} ; 13,17 \mathrm{r}-18 \mathrm{v}\end{array}$ \\
\hline BARBA, Juan & presbítero & Valencia & - & $1469-\mathrm{V}-2$ & procura & A. Barbens, 1, 26r-27r \\
\hline BENAPRES, Miguel & $\begin{array}{l}\text { estudiante } \\
\text { de arte }\end{array}$ & Valencia & - & 1468-XII-18 & Testigo & A. Barbens, 1, 12r-v \\
\hline $\begin{array}{l}\text { BERENGUER, Mosen } \\
\text { Jaime }\end{array}$ & - & Aragón & - & 1498-III-9 & Testigo & G. Carnicer, $1,5 \mathrm{v}$ \\
\hline BERTRÁN, Hugo & ciudadano & Valencia & $\begin{array}{c}\text { Castillo de } \\
\text { Cagliari } \\
\text { (degens })\end{array}$ & 1483-II-16 & Procura & A. Barbens, 9, 3r-v \\
\hline BERTRÁN, Jaime & mercader & Valencia & - & $1443-\mathrm{V}-31$ & Procura & G. Garau, $1,65 \mathrm{v}$ \\
\hline BERTRÁN, Jaime & $\begin{array}{l}\text { abuelo de J. } \\
\text { Bertrán }\end{array}$ & Valencia & - & $1443-V-31$ & Procura & G. Garau, $1,65 \mathrm{v}$ \\
\hline BERTRÁN, Juan & $\begin{array}{l}\text { padre de J. } \\
\text { Bertrán }\end{array}$ & Valencia & - & $1443-V-31$ & Procura & G. Garau, $1,65 \mathrm{v}$ \\
\hline BERTRÁN, Martín & mercader & Valencia & - & 1469-IX-18 & Procura & A. Barbens, 1, 39v-40r \\
\hline $\begin{array}{l}\text { BLASCO (menor de } \\
\text { edad) }\end{array}$ & ciudadano & Valencia & - & $1443-V-28$ & $\begin{array}{c}\text { Extinción } \\
\text { deuda }\end{array}$ & G. Garau, 1, 63r \\
\hline BLASCO, Bartolomé & $\begin{array}{l}\text { difunto } \\
\text { mercader } \\
\text { (abuelo) }\end{array}$ & Valencia & - & $\begin{array}{c}1443-\mathrm{V}-28 / \\
\text { VII-29 }\end{array}$ & $\begin{array}{c}\text { Extinción } \\
\text { deuda / } \\
\text { testigo }\end{array}$ & G. Garau, $1,63 \mathrm{r}$ y $69 \mathrm{r}$ \\
\hline BONAN, Juan & sastre & Valencia & - & 1468-VIII-6 & Comanda & A. Barbens, $1,2 \mathrm{r}-2 \mathrm{v}$ \\
\hline BONET, Bonacato & colchonero & Valencia & - & $1469-X I-6$ & Procura & A. Barbens, $1,43 \mathrm{r}-44 \mathrm{r}$ \\
\hline BONET, Leonor & $\begin{array}{l}\text { viuda de J. } \\
\text { Ventura }\end{array}$ & Valencia & - & 1469-XI-6 & Procura & A. Barbens, 1, 43r-44r \\
\hline BONO, Jacobo & agricultor & Valencia & $\begin{array}{c}\text { Castillo de } \\
\text { Cagliari } \\
\text { (degens) }\end{array}$ & $\begin{array}{c}1468-\mathrm{X}- \\
8 / 15 \text { y XI- } \\
28\end{array}$ & $\begin{array}{l}\text { Procura / } \\
\text { préstamo }\end{array}$ & $\begin{array}{c}\text { A. Barbens, } 1,3 \mathrm{r}, 3 \mathrm{v}-4 \mathrm{r} \text {, } \\
9 \mathrm{v}-10 \mathrm{r}\end{array}$ \\
\hline BONO, Úrsula & $\begin{array}{l}\text { viuda de J. } \\
\text { Bono }\end{array}$ & Valencia & Cagliari & $\begin{array}{c}1468-X- \\
8 / 15 \\
\text { y XI-28 } \\
\end{array}$ & $\begin{array}{l}\text { Procura / } \\
\text { préstamo }\end{array}$ & $\begin{array}{c}\text { A. Barbens, } 1,3 \mathrm{r}, 3 \mathrm{v}-4 \mathrm{r} \text {, } \\
9 \mathrm{v}-10 \mathrm{r}\end{array}$ \\
\hline BOTELLER, Bernardo & presbítero & Nules & - & $1455-\mathrm{VII}-17$ & procura & G. Garau, 2, 145r \\
\hline CABANES, Pedro & mercader & Valencia & - & 1454-IX-3 & Testigo & G. Garau, 2, 23r \\
\hline CACONELLA, Andrés & habitante & Valencia & - & $1484-\mathrm{VII}-20$ & Testigo & A. Barbens, $15,134 \mathrm{r}$ \\
\hline CAFONT, Guillermo & mercader & Valencia & - & 1487-VII-24 & Venta & M. Leytago, $2,101 \mathrm{v}$ \\
\hline CALAHORRA, Pedro & notario & Valencia & - & $1455-\mathrm{I}-20$ & Procura & S. d'Aranda, $3,10 \mathrm{v}-11 \mathrm{r}$ \\
\hline CALBET, Bernardo & marinero & Valencia & - & 1482-IV-16 & Deuda & A. Barbens, $12,25 \mathrm{r}$ \\
\hline CALBO, Pedro de & notario & $\begin{array}{c}\text { Aldrazo } \\
\text { (Comunidad } \\
\text { de Daroca) }\end{array}$ & - & $1441-V-3$ & $\begin{array}{c}\text { Extinción } \\
\text { deuda }\end{array}$ & G. Garau, 1, 2r-v \\
\hline CAMARENA, Juan & $\begin{array}{l}\text { maestro de } \\
\text { arte }\end{array}$ & Valencia & - & 1474-VII-7 & Procura & A. Barbens, $5,13 \mathrm{r}-14 \mathrm{r}$ \\
\hline CAPERMAIES, Pablo & notario & Valencia & - & 1463-IV-16 & Procura & P. Durante, $2,45 r-46 r$ \\
\hline CARBO, Pedro & marinero & Valencia & & $1470-\mathrm{V}-24$ & Testigo & A. Barbens, $2,5 \mathrm{v}-6 \mathrm{v}$ \\
\hline CARNIÇER, Juan & escribano & $\begin{array}{l}\text { Maella } \\
\text { (Aragón) }\end{array}$ & - & 1477-VII-22 & Testigo & A. Barbens, $10,8 \mathrm{v}$ \\
\hline CATALÁN, Guillermo & mercader & Valencia & - & 1470-IX-30 & Testigo & A. Barbens, $13,42 \mathrm{v}$ \\
\hline CERVERA, Manuel & sastre & Valencia & - & $\begin{array}{c}\text { 1470-VI-19 } \\
\text { / IX-30 }\end{array}$ & Procura & $\begin{array}{c}\text { A. Barbens, } 2,20 \mathrm{v} / 13, \\
25 \mathrm{r} \text { y } 42 \mathrm{v}\end{array}$ \\
\hline CIFRO, Ferraio & - & La Jana & - & 1441-XII-10 & Delegación & G. Garau, $1,14 \mathrm{r}$ \\
\hline
\end{tabular}




\begin{tabular}{|c|c|c|c|c|c|c|}
\hline & & (Valencia) & & & & \\
\hline CLAVER, Pedro & $\begin{array}{l}\text { doctor en } \\
\text { leyes }\end{array}$ & Zaragoza & $\begin{array}{l}\text { Castillo de } \\
\text { Cagliari } \\
\text { (morador) }\end{array}$ & 1480-IV-12 & Indulgencia & A. Barbens, $14,23 \mathrm{r}-23 \mathrm{v}$ \\
\hline COLOMER, Francisco & mercader & Valencia & - & 1469-IX-18 & Procura & A. Barbens, $1,39 \mathrm{v}-40 \mathrm{r}$ \\
\hline CONOBI, Enrique & clérigo & Aragón & $\begin{array}{l}\text { proveniente } \\
\text { de Cagliari }\end{array}$ & $1484-X-17$ & procura & M. Leytago, 1, 28v \\
\hline COSTELLS, Jaime & ciudadano & Valencia & $\begin{array}{l}\text { Castillo de } \\
\text { Cagliari } \\
\text { (residente) }\end{array}$ & $1442-\mathrm{XI}-26$ & Delegación & G. Garau, $1,48 \mathrm{v}$ \\
\hline CRISTÓBAL, ¿? & & Valencia & - & $1455-\mathrm{I}-24$ & Testigo & S. d'Aranda, $3,13 \mathrm{v}$ \\
\hline DAMEISO, Pedro & - & Aragón & - & 1486-V-14 & Testigo & M. Leytago, $2,65 \mathrm{r}$ \\
\hline DE CETINA, Sancho & escudero & Valencia & - & 1469-VI-19 & Testigo & A. Barbens, $1,32 \mathrm{v}$ \\
\hline DE FARIZA, Gabriel & notario & Alcorisa & - & 1481-III-19 & $\begin{array}{l}\text { Dotación } \\
\text { de capilla }\end{array}$ & A. Barbens, $14,86 \mathrm{r}-\mathrm{v}$ \\
\hline DE FRANÇA, Jacobo & mercader & Valencia & $\begin{array}{l}\text { Castillo de } \\
\text { Cagliari } \\
\text { (morador) }\end{array}$ & $1479-X-20$ & Procura & A. Barbens, $11,59 \mathrm{v}$ \\
\hline DE JAHEN, Alfonso & sastre & Valencia & - & 1469-IX-18 & Testigo & A. Barbens, 1, 40r \\
\hline $\begin{array}{l}\text { DE LA VETLA, } \\
\text { Bernardo }\end{array}$ & mercader & Aragón & - & 1482-IV-26 & Testigo & A. Barbens, $12,28 \mathrm{v}$ \\
\hline DE VILARASSA, Juan & $\begin{array}{l}\text { 'miles } \\
\text { iusticie' }\end{array}$ & Valencia & - & 1468-VIII-6 & Comanda & A. Barbens, $1,2 \mathrm{r}-2 \mathrm{v}$ \\
\hline DEL PUERTO, Pedro & mercader & Valencia & - & 1468-XI-28 & Testigo & A. Barbens, $1,9 \mathrm{v}-10 \mathrm{r}$ \\
\hline DEMNAT, Pedro & notario & $\begin{array}{l}\text { Salsadella } \\
\text { (Valencia) }\end{array}$ & $\begin{array}{c}\text { Castillo de } \\
\text { Cagliari } \\
\text { (ciudadano) }\end{array}$ & 1441-XII-10 & Delegación & G. Garau, 1, 14r \\
\hline DEMNAT, Pedro & - & $\begin{array}{l}\text { Salsadella } \\
\text { (Valencia) }\end{array}$ & - & 1441-XII-10 & Delegación & G. Garau, 1, 14r \\
\hline DESPLÁ, Jaime & mercader & Valencia & - & $1443-\mathrm{V}-31$ & Procura & G. Garau, $1,65 \mathrm{v}$ \\
\hline DEVITS, Pere & marinero & Valencia & - & 1456-XII-24 & Testigo & P. Steve, $1,16 \mathrm{v}$ \\
\hline DIEBRA, Fernando & $\begin{array}{l}\text { rector y } \\
\text { párroco }\end{array}$ & $\begin{array}{l}\text { Ulldemolins } \\
\text { (Diócesis de } \\
\text { Tarragona) }\end{array}$ & - & 1458-IV-24 & $\begin{array}{c}\text { Declaración } \\
\text { de } \\
\text { paternidad }\end{array}$ & P. Steve, $1,44 \mathrm{r}-\mathrm{v}$ \\
\hline DIEZ, Bernardo & mercader & Valencia & - & 1455-VII-14 & $\begin{array}{l}\text { Letra de } \\
\text { cambio }\end{array}$ & G. Garau, 2, 140v \\
\hline DURÁN, Pedro & 'apuntator' & Valencia & - & $\begin{array}{c}1479-\text { II- } 8 \text { y } \\
\text { V-4 }\end{array}$ & Testigo & $\begin{array}{c}\text { A. Barbens, 6, 13r; 11, } \\
24 \mathrm{r}\end{array}$ \\
\hline DURREA, Antonio & - & Daroca & $\begin{array}{c}\text { Castillo de } \\
\text { Cagliari } \\
(\text { domiciliado })\end{array}$ & 1498-III-9 & Testamento & G. Carnicer, 1, 4v-5v \\
\hline FAVOLLOSA, Juan & mercader & Valencia & - & 1479-VI-14 & Testigo & A. Barbens, $11,69 \mathrm{r}$ \\
\hline FERDINANDI, Jacobo & notario & Valencia & - & $1469-\mathrm{V}-31$ & Procura & A. Barbens, 1, 28v-29r \\
\hline $\begin{array}{l}\text { FERNÁNDEZ DE } \\
\text { HEREDIA, Pedro }\end{array}$ & $\begin{array}{c}\text { baile y } \\
\text { soldado del } \\
\text { Hospital de } \\
\text { San Juan de } \\
\text { Jerusalén } \\
\end{array}$ & Cantavieja & - & 1480-IV-12 & Indulgencia & A. Barbens, 14, 23r-v \\
\hline FERRAIO, Juan & Mercader & Valencia & - & $1469-X I-6$ & Procura & A. Barbens, $1,43 r-44 r$ \\
\hline FERRAIO, Luis & Mercader & Valencia & - & $1469-X I-6$ & Procura & A. Barbens, $1,43 \mathrm{r}-44 \mathrm{r}$ \\
\hline FORTÚN, Guillermo & habitante & Gandía & - & $1443-\mathrm{V}-28$ & Delegación & G. Garau, 1, 64r-v \\
\hline FRANCH, Catalina & $\begin{array}{c}\text { esposa de P. } \\
\text { Steve (hija } \\
\text { de doña } \\
\text { Constanza y } \\
\text { de Jacobo) }\end{array}$ & Alicante & $\begin{array}{l}\text { Cagliari } \\
\text { (residente) }\end{array}$ & 1458-VII-28 & procura & P. Steve, $1,48 \mathrm{r}-50 \mathrm{v}$ \\
\hline FRANCH, Jacobo & $\begin{array}{l}\text { mercader } \\
\text { (padre de C. } \\
\text { Franch) } \\
\end{array}$ & Alicante & - & 1458-VII-28 & Procura & P. Steve, $1,48 \mathrm{r}-50 \mathrm{v}$ \\
\hline FUSTER, Juan & coralero & Valencia & - & 1469-VI-19 & Procura & A. Barbens, $1,32 \mathrm{r}-32 \mathrm{v}$ \\
\hline GALBES, Miguel & presbítero & Valencia & - & 1455-IX-12 & procura & G. Garau, 2, 167r \\
\hline GAMBAY, Bartolomé & aduanero & Valencia & $\begin{array}{l}\text { Castillo de } \\
\text { Cagliari } \\
\text { (residente) }\end{array}$ & 1474-III-6 & Dote & A. Barbens, $4,12 \mathrm{v}-13 \mathrm{r}$ \\
\hline GARCÍA, Juan & $\begin{array}{l}\text { mercader / } \\
\text { flazadero }\end{array}$ & Valencia & $\begin{array}{l}\text { Castillo de } \\
\text { Cagliari } \\
\text { (morador) }\end{array}$ & $\begin{array}{l}1483-\text { III-8 / } \\
1482-\mathrm{X}-31\end{array}$ & $\begin{array}{c}\text { Procura / } \\
\text { testigo }\end{array}$ & $\begin{array}{c}\text { A. Barbens, } 9,12 \mathrm{r}-12 \mathrm{v} / \\
12,72 \mathrm{r}\end{array}$ \\
\hline GARCÍA, Luis & escribano & Valencia & - & $1469-X-6$ & Procura & A. Barbens, $1,40 \mathrm{v}-41 \mathrm{r}$ \\
\hline GIL, Antonio & ciudadano & Valencia & - & $1463-I-3$ & Testigo & P. Durante, $2,7 \mathrm{v}$ \\
\hline GRAS, Antonio & mercader & Valencia & - & 1477-VII-28 & Testigo / & A. Barbens, 10, 10r; 6, \\
\hline
\end{tabular}




\begin{tabular}{|c|c|c|c|c|c|c|}
\hline & & & & $\begin{array}{c}\text { /1479-I-1 y } \\
\text { IV-22 }\end{array}$ & $\begin{array}{l}\text { testamento } \\
\text { / Procura }\end{array}$ & $4 \mathrm{r}-5 \mathrm{r} ; 11,2 \mathrm{r}-3 \mathrm{v}$ y $21 \mathrm{r}-\mathrm{v}$ \\
\hline GRAS, Nicolás & mercader & Valencia & $\begin{array}{l}\text { Castillo de } \\
\text { Cagliari } \\
\text { (habitante) }\end{array}$ & $\begin{array}{l}\text { 1474-VIII- } \\
17 / 1479-I-1\end{array}$ & $\begin{array}{l}\text { Deuda / } \\
\text { testamento }\end{array}$ & $\begin{array}{c}\text { A. Barbens, } 5,27 \mathrm{r}-27 \mathrm{v} / \\
6,4 \mathrm{r}-5 \mathrm{r} \text { y } 11,2 \mathrm{r}-3 \mathrm{v}\end{array}$ \\
\hline GUALIS, Guillermo & mercader & Valencia & - & $1473-\mathrm{I}-28$ & Deuda & A. Barbens, 3, 3r-v \\
\hline GUILL, Fernando & $\begin{array}{c}\text { difunto } 2^{\circ} \\
\text { marido de } \\
\text { Juana } \\
\text { (madre del } \\
\text { notario P. } \\
\text { Steve) }\end{array}$ & Alicante & - & $1458-\mathrm{VII}-28$ & Procura & P. Steve, $1,48 \mathrm{r}-50 \mathrm{v}$ \\
\hline GUILL, Jacobo & $\begin{array}{l}\text { hermano de } \\
\text { Fernando }\end{array}$ & Alicante & - & $1458-\mathrm{VII}-28$ & Procura & P. Steve, $1,48 \mathrm{r}-50 \mathrm{v}$ \\
\hline JORNET, Juan & doncel & Valencia & - & 1441-VI-24 & Testigo & G. Garau, 1, 3r \\
\hline $\begin{array}{l}\text { JUAN DE PERTUSA, } \\
\text { Pedro }\end{array}$ & mercader & Valencia & - & $1455-\mathrm{I}-15$ & $\begin{array}{l}\text { Deuda / } \\
\text { Procura }\end{array}$ & $\begin{array}{c}\text { S. d'Aranda, 3, 9v y } \\
10 \mathrm{v}-11 \mathrm{r}\end{array}$ \\
\hline Juana & $\begin{array}{l}\text { mujer de B. } \\
\text { Steve }\end{array}$ & Alicante & - & $1458-\mathrm{VII}-28$ & Procura & P. Steve, $1,48 \mathrm{r}-50 \mathrm{v}$ \\
\hline $\begin{array}{l}\text { LUPI DEL FRAGO, } \\
\text { Juan }\end{array}$ & notario & Zaragoza & - & $1482-X-16$ & Censo & A. Barbens, 12, 66r-v \\
\hline $\begin{array}{l}\text { MAÇA DELICANO, } \\
\text { Pedro }\end{array}$ & ciudadano & Valencia & - & $1480-\mathrm{XI}-10$ & Beneficio & A. Barbens, $14,10 \mathrm{v}-11 \mathrm{r}$ \\
\hline MAÇANA, Juan & mercader & Valencia & - & 1479-III-8 & Préstamo & $\begin{array}{c}\text { A. Barbens, 6, 24r-24v y } \\
11,13 \mathrm{r}-13 \mathrm{v}\end{array}$ \\
\hline Maestro Juan & sastre & Valencia & - & $1443-\mathrm{V}-28$ & Testigo & G. Garau, 1, 62v \\
\hline MARTÍN, Antonio & ciudadano & Valencia & - & 1441-XII-10 & Testigo & G. Garau, $1,14 \mathrm{r}$ \\
\hline MARTÍN, Bartolomé & $\begin{array}{l}\text { patrón de } \\
\text { barco }\end{array}$ & Valencia & $\begin{array}{l}\text { Castillo de } \\
\text { Cagliari } \\
\text { (habitante) }\end{array}$ & 1442-XI-29 & $\begin{array}{l}\text { Compra- } \\
\text { venta }\end{array}$ & G. Garau, $1,52 \mathrm{v}-53 \mathrm{r}$ \\
\hline MONPAHO, Gabriel & mercader & Morella & - & $1477-V I I-22$ & Testigo & A. Barbens, $10,8 \mathrm{v}$ \\
\hline MOROS, Bernardo & mercader & Valencia & - & 1481-II-5 & Testigo & A. Barbens, $8,8 \mathrm{v}$ \\
\hline $\begin{array}{l}\text { NAVARRO DE } \\
\text { NAVARRET, Luis }\end{array}$ & mercader & Valencia & - & 1487-IX-4 & procura & M. Leytago, 2, 114r \\
\hline NAVARRO, García & mercader & Valencia & $\begin{array}{l}\text { Castillo de } \\
\text { Cagliari } \\
\text { (residente) }\end{array}$ & $\begin{array}{c}1463-\mathrm{IX}-2 \\
1468-\mathrm{X}-15 / \\
1469-\mathrm{V}-31\end{array}$ & $\begin{array}{c}\text { Letra de } \\
\text { cambio / } \\
\text { préstamo / } \\
\text { testigo }\end{array}$ & $\begin{array}{c}\text { P. Durante, } 2,103 \mathrm{r}- \\
103 \mathrm{v} \\
\text { A. Barbens, } 1,3 \mathrm{v}-4 \mathrm{r} \text { y } \\
29 \mathrm{r}\end{array}$ \\
\hline $\begin{array}{l}\text { NAVARRO, } \\
\text { Guillermo }\end{array}$ & mercader & Valencia & - & 1479-IX-11 & Procura & A. Barbens, $11,49 \mathrm{r}$ \\
\hline OLALIA, Miguel de & notario & $\begin{array}{c}\text { Aldrazo } \\
\text { (Comunidad } \\
\text { de Daroca) } \\
\end{array}$ & - & $1441-V-3$ & $\begin{array}{l}\text { Extinción } \\
\text { deuda }\end{array}$ & G. Garau, 1, 2r-v \\
\hline PARDO, Raimundo & mercader & Valencia & $\begin{array}{c}\text { Castillo de } \\
\text { Cagliari } \\
\text { (habitante) } \\
\end{array}$ & $\begin{array}{c}1469-V-31 / \\
\text { VI-15/22 }\end{array}$ & $\begin{array}{l}\text { Procura / } \\
\text { Venta }\end{array}$ & $\begin{array}{c}\text { A. Barbens, } 1,28 v-29 r \text {, } \\
30 v, 35 v-37 r\end{array}$ \\
\hline PELEGRI, Antonio & agricultor & Valencia & - & $1468-\mathrm{X}-8$ & Procura & A. Barbens, $1,3 \mathrm{r}$ \\
\hline PELEGRI, Francisca & $\begin{array}{l}\text { Hija de A. } \\
\text { Pelegri y Ú. } \\
\text { Bono }\end{array}$ & Valencia & - & $1468-X-8$ & Procura & A. Barbens, $1,3 \mathrm{r}$ \\
\hline PELEGRI, Jacobo & vicecanciller & Aragón & - & $1441-V-3$ & $\begin{array}{c}\text { Extinción } \\
\text { deuda }\end{array}$ & G. Garau, 1, 2r-v \\
\hline PERALTA, Damián & mercader & Valencia & $\begin{array}{l}\text { Castillo de } \\
\text { Cagliari } \\
\text { (habitante) }\end{array}$ & $\begin{array}{l}1469-V-31 \\
\text { y VI-12/22 }\end{array}$ & Procura & $\begin{array}{c}\text { A. Barbens, } 1,28 \mathrm{v}-29 \mathrm{r} \text {, } \\
29 \mathrm{v}, 34 \mathrm{v}-35 \mathrm{r}\end{array}$ \\
\hline $\begin{array}{l}\text { PÉREZ DEL ROYO, } \\
\text { Miguel }\end{array}$ & especiero & Valencia & - & 1469-VI-12 & $\begin{array}{c}\text { Procura / } \\
\text { testigo }\end{array}$ & A. Barbens, $1,29 \mathrm{v}, 30 \mathrm{r}$ \\
\hline PÉREZ, Francisco & mercader & Valencia & - & 1483-III-8 & Procura & A. Barbens, 9, 12r-v \\
\hline PÉREZ, Luis & $\begin{array}{l}\text { especiero y } \\
\text { mercader }\end{array}$ & Valencia & - & $1468-\mathrm{XI}-28$ & Procura & A. Barbens, $1,9 \mathrm{v}-10 \mathrm{r}$ \\
\hline PÉREZ, Miguel & especiero & Valencia & - & 1469-VI-22 & Testigo & A. Barbens, 1, 35r \\
\hline $\begin{array}{l}\text { PERPIÑÀN, } \\
\text { Bartolomé }\end{array}$ & $\begin{array}{l}\text { patrón de } \\
\text { barco }\end{array}$ & Valencia & - & 1468-VIII-6 & Comanda & A. Barbens, 1, 2r-v \\
\hline PIPINELLO, Francisco & mercader & Valencia & - & $1480-\mathrm{XI}-3$ & Testigo & A. Barbens, $14,8 \mathrm{r}$ \\
\hline PONS, Martín & ciudadano & Valencia & - & 1455-VI-12 & Procura & G. Garau, 2, 124v-125r \\
\hline PONTE, Gabriel & ciudadano & Valencia & - & 1455-IV-30 & Comanda & S. d'Aranda, 3, 43r \\
\hline Raimundete & - & $\begin{array}{l}\text { Salsadella } \\
\text { (Valencia) }\end{array}$ & - & 1441-XII-10 & Delegación & G. Garau, 1, 14r \\
\hline $\begin{array}{l}\text { RAMÓN URREGIO, } \\
\text { Antonio }\end{array}$ & correjero & Valencia & - & $\begin{array}{c}1443-\mathrm{II}-20 / \\
1469-\mathrm{X}-6\end{array}$ & $\begin{array}{l}\text { Compra- } \\
\text { venta / }\end{array}$ & $\begin{array}{l}\text { G. Garau, } 1,57 \mathrm{r}-57 \mathrm{v} / \\
\text { A. Barbens, } 1,40 \mathrm{v}-41 \mathrm{r}\end{array}$ \\
\hline
\end{tabular}




\begin{tabular}{|c|c|c|c|c|c|c|}
\hline & & & & & procura & \\
\hline RAMÓN, Bartolomé & $\begin{array}{l}\text { estudiante } \\
\text { de arte }\end{array}$ & Valencia & $\begin{array}{c}\text { Castillo de } \\
\text { Cagliari } \\
\text { (habitante) }\end{array}$ & $\begin{array}{l}\text { 1468-XII-18 } \\
/ 1469-X-6\end{array}$ & $\begin{array}{l}\text { Testigo / } \\
\text { procura }\end{array}$ & $\begin{array}{c}\text { A. Barbens, } 1,12 \mathrm{r}-12 \mathrm{v}, \\
40 \mathrm{v}-41 \mathrm{r}\end{array}$ \\
\hline ROBIOLS, Juan & escribano & Valencia & $\begin{array}{l}\text { Castillo de } \\
\text { Cagliari } \\
\text { (degens) }\end{array}$ & 1468-XII-18 & Deuda & A. Barbens, 1, 12r-v \\
\hline ROCA, Miguel & - & Valencia & - & $1457-X I I-30$ & $\begin{array}{l}\text { Cesión de } \\
\text { crédito }\end{array}$ & P. Steve, $1,17 \mathrm{r}$ \\
\hline ROIÇ, Juan & mercader & Valencia & - & $\begin{array}{l}1469-\text { VI- } \\
12 / 15 / 22 \\
\end{array}$ & $\begin{array}{l}\text { Testigo / } \\
\text { procura }\end{array}$ & $\begin{array}{l}\text { A. Barbens, } 1,29 \mathrm{v}, 30 \mathrm{r} \text {, } \\
30 \mathrm{v}, 34 \mathrm{v}-35 \mathrm{r}, 37 \mathrm{r}\end{array}$ \\
\hline ROMEO, Salvador & sastre & Valencia & $\begin{array}{l}\text { Castillo de } \\
\text { Cagliari } \\
\text { (degentes) }\end{array}$ & 1469-XII-29 & Deuda & A. Barbens, 13, 1r \\
\hline ROSSELL, Luis & presbítero & Játiva & - & $1483-\mathrm{XI}-16$ & Concordia & A. Barbens, $15,78 \mathrm{r}$ \\
\hline ROSSELLÓ, Juan & presbítero & Segorbe & - & 1474-VII-7 & Procura & A. Barbens, $5,13 \mathrm{r}-14 \mathrm{r}$ \\
\hline $\begin{array}{l}\text { RUIZ DE MOROS, } \\
\text { Guillermo }\end{array}$ & - & Zaragoza & - & $\begin{array}{l}\text { 1487-VIII- } \\
31\end{array}$ & Procura & M. Leytago, 2, 112v \\
\hline SALVAT, Antonio & ciudadano & Valencia & $\begin{array}{l}\text { Castillo de } \\
\text { Cagliari } \\
(\text { degens })\end{array}$ & $\begin{array}{l}1468-\mathrm{X}- \\
8 / 15\end{array}$ & $\begin{array}{l}\text { Procura / } \\
\text { préstamo }\end{array}$ & A. Barbens, $1,3 \mathrm{r}, 3 \mathrm{v}-4 \mathrm{r}$ \\
\hline SANXIS, Martín & mercader & Aragón & - & $1480-X I I-5$ & $\begin{array}{c}\text { Licencia } \\
\text { matrimonio }\end{array}$ & A. Barbens, $14,16 \mathrm{v}$ \\
\hline SANZ, Antonio & mercader & Valencia & - & 1474-VII-30 & Venta & A. Barbens, 5, 22v-23r \\
\hline SANZ, Luis & doncel & Aragón & - & $1484-\mathrm{V}-26$ & procura & M. Leytago, $1,38 \mathrm{r}$ \\
\hline SEBAL, Juan & doncel & Zaragoza & $\begin{array}{l}\text { Castillo de } \\
\text { Cagliari } \\
\text { (morador) }\end{array}$ & $\begin{array}{c}1482-\mathrm{X}-16 / \\
\mathrm{XI}-14\end{array}$ & Censo & $\begin{array}{c}\text { A. Barbens, } 12,66 r-66 v \\
\text { y } 82 v-83 r\end{array}$ \\
\hline SEBASTIÁN, Mateo & jurisperito & Nules & $\begin{array}{c}\text { Moram } \\
\text { trahens in } \\
\text { Castro } \\
\text { Callari }\end{array}$ & 1455-VII-17 & procura & G. Garau, 2, 145r \\
\hline SENYOR, Juan & portero real & Valencia & - & $1473-I-26$ & Testigo & A. Barbens, 3, 2v-3r \\
\hline SOLER, Lorenzo & mercader & Valencia & - & 1455-VI-12 & procura & G. Garau, 2, 124v-125r \\
\hline SOLER, Luis & mercader & Valencia & - & $1455-\mathrm{VI}-12$ & procura & G. Garau, $2,124 \mathrm{v}-125 \mathrm{r}$ \\
\hline SOLSONA, Bernardo & mercader & Valencia & - & $\begin{array}{c}1469-\mathrm{VI}- \\
15 / 22 \text { y IX- } \\
18 \\
\end{array}$ & $\begin{array}{l}\text { Procura / } \\
\text { testigo }\end{array}$ & $\begin{array}{l}\text { A. Barbens, 1, 30r, 30v, } \\
32 \mathrm{r}-32 \mathrm{v}, 35 \mathrm{r}, 39 \mathrm{v}-40 \mathrm{r}\end{array}$ \\
\hline SOSPREDA, Beatriz & $\begin{array}{l}\text { Hija del } \\
\text { difunto G. } \\
\text { Sospreda }\end{array}$ & Valencia & - & $1480-\mathrm{XI}-10$ & Beneficio & A. Barbens, $14,10 \mathrm{v}-11 \mathrm{r}$ \\
\hline $\begin{array}{l}\text { SOSPREDA, } \\
\text { Guillermo }\end{array}$ & ciudadano & Valencia & - & $1480-\mathrm{XI}-10$ & Beneficio & A. Barbens, $14,10 \mathrm{v}-11 \mathrm{r}$ \\
\hline SPLUGUES, Juan & mercader & Valencia & $\begin{array}{c}\text { Castillo de } \\
\text { Cagliari } \\
\text { (habitante) }\end{array}$ & $\begin{array}{l}\text { 1469-XI-6/ } \\
\text { XII-29 }\end{array}$ & $\begin{array}{c}\text { Procura / } \\
\text { deuda }\end{array}$ & $\begin{array}{c}\text { A. Barbens, } 1,43 \mathrm{r}-44 \mathrm{r} / \\
13,1 \mathrm{r}\end{array}$ \\
\hline STEVE, Bernardo & $\begin{array}{c}\text { notario } \\
\text { (padre de P. } \\
\text { Steve) }\end{array}$ & Játiva & - & 1458-VII-28 & Procura & P. Steve, $1,48 \mathrm{r}-50 \mathrm{v}$ \\
\hline STEVE, Francisco & mercader & Valencia & - & 1479-VII-5 & $\begin{array}{c}\text { Doc. } \\
\text { incompleto }\end{array}$ & A. Barbens, $11,39 \mathrm{r}$ \\
\hline STEVE, Jacobo & $\begin{array}{c}\text { notario } \\
\text { (hermano de } \\
\text { P. Steve) }\end{array}$ & Játiva & - & $1457-$ II -15 & Testigo & P. Steve, $1,18 \mathrm{r}$ \\
\hline STEVE, Pedro & notario & Játiva & $\begin{array}{c}\text { Cagliari } \\
\text { (residente) }\end{array}$ & 1458-VII-28 & Procura & P. Steve, $1,48 \mathrm{r}-50 \mathrm{v}$ \\
\hline THOLSO, Luis & doncel & Valencia & - & 1479-XI-12 & Testigo & A. Barbens, $11,63 \mathrm{r}$ \\
\hline TONIANI, Antonio & mercader & Valencia & $\begin{array}{l}\text { Castillo de } \\
\text { Cagliari } \\
\text { (morador) }\end{array}$ & 1479-IX-9 & Venta & A. Barbens, $11,48 \mathrm{r}-\mathrm{v}$ \\
\hline TORRELLO, Juan & ciudadano & Valencia & $\begin{array}{c}\text { Alghero } \\
\text { (habitante) }\end{array}$ & 1442-III-27 & Testigo & G. Garau, $1,22 \mathrm{v}$ \\
\hline UGUART, Pedro & mercader & Valencia & $\begin{array}{l}\text { Castillo de } \\
\text { Cagliari } \\
\text { (habitante) }\end{array}$ & $1470-V-26$ & Procura & A. Barbens, 2, 8r-v \\
\hline $\begin{array}{l}\text { VALENCIANA, } \\
\text { Catalina }\end{array}$ & $\begin{array}{l}\text { hija de } \\
\text { Alcarás }\end{array}$ & Valencia & - & 1487-VII-24 & Venta & M. Leytago, 2, 101v \\
\hline VENTURA, Jacobo & colchonero & Valencia & - & $\begin{array}{c}1469-X I-6 / \\
\text { XII-29 }\end{array}$ & $\begin{array}{c}\text { Procura / } \\
\text { deuda }\end{array}$ & $\begin{array}{c}\text { A. Barbens, } 1,43 \mathrm{r}-44 \mathrm{r} / \\
13,1 \mathrm{r}\end{array}$ \\
\hline VIDAL, Juan & - & Calatayud & - & 1486-III-8 & Exención & M. Leytago, $1,60 \mathrm{v}$ \\
\hline
\end{tabular}




\begin{tabular}{|l|c|c|c|c|c|c|}
\hline & & & & & deuda & \\
\hline $\begin{array}{l}\text { VILLARREAL, } \\
\text { Gaspar }\end{array}$ & mercader & Valencia & - & $\begin{array}{c}1487-\text { II-3/ } \\
\text { V-11 }\end{array}$ & $\begin{array}{c}\text { Venta } \\
\text { esclavo / } \\
\text { exención } \\
\text { deuda }\end{array}$ & $\begin{array}{c}\text { M. Leytago, 2, 83r } / \\
88 \mathrm{r}-\mathrm{v}\end{array}$ \\
\hline VINES, Juan & $\begin{array}{c}\text { estudiante } \\
\text { de arte }\end{array}$ & Valencia & - & $1474-$ VII-7 & Procura & A. Barbens, 5, 13r-14r \\
\hline $\begin{array}{l}\text { VINYOLES, Arcis } \\
(=\text { Narciso })\end{array}$ & ciudadano & Valencia & - & $1482-$ III-28 & Intimación & A. Barbens, 12, 23r \\
\hline XALPES, Martín & carpintero & Valencia & - & $1469-$ V-4 & Procura & A. Barbens, 1, 27r-v \\
\hline
\end{tabular}

